OPEN ACCESS

Edited by:

Humberto Lanz-Mendoza, National Institute of Public Health, Mexico

Reviewed by:

Francisco José Reynaldi, Consejo Nacional de Investigaciones Científicas y Técnicas (CONICET), Argentina

Gloria Ruiz Guzmán, Universidad Nacional Autónoma de

México, Mexico Esmaeil Amiri

University of North Carolina at Greensboro, United States

${ }^{*}$ Correspondence: Michelle L. Flenniken michelle.flenniken@montana.edu

Specialty section:

This article was submitted to Comparative Immunology, a section of the journal

Frontiers in Immunology

Received: 02 August 2021 Accepted: 11 October 2021 Published: 28 October 2021

Citation:

Parekh F, Daughenbaugh KF and Flenniken ML (2021) Chemical Stimulants and Stressors Impact the Outcome of Virus Infection and Immune Gene Expression in Honey Bees (Apis mellifera).

Front. Immunol. 12:747848. doi: 10.3389/fimmu.2021.747848

\section{Chemical Stimulants and Stressors Impact the Outcome of Virus Infection and Immune Gene Expression in Honey Bees (Apis mellifera)}

\author{
Fenali Parekh ${ }^{1,2,3}$, Katie F. Daughenbaugh ${ }^{2,3}$ and Michelle L. Flenniken ${ }^{1,2,3 *}$ \\ ${ }^{1}$ Department of Microbiology and Immunology, Montana State University, Bozeman, MT, United States, ${ }^{2}$ Department of \\ Plant Sciences and Plant Pathology, Montana State University, Bozeman, MT, United States, ${ }^{3}$ Pollinator Health Center, \\ Montana State University, Bozeman, MT, United States
}

Western honey bees (Apis mellifera) are ecologically, agriculturally, and economically important plant pollinators. High average annual losses of honey bee colonies in the US have been partially attributed to agrochemical exposure and virus infections. To examine the potential negative synergistic impacts of agrochemical exposure and virus infection, as well as the potential promise of phytochemicals to ameliorate the impact of pathogenic infections on honey bees, we infected bees with a panel of viruses (i.e., Flock House virus, deformed wing virus, or Sindbis virus) and exposed to one of three chemical compounds. Specifically, honey bees were fed sucrose syrup containing: (1) thyme oil, a phytochemical and putative immune stimulant, (2) fumagillin, a beekeeper applied fungicide, or (3) clothianidin, a grower-applied insecticide. We determined that virus abundance was lower in honey bees fed $0.16 \mathrm{ppb}$ thyme oil augmented sucrose syrup, compared to bees fed sucrose syrup alone. Parallel analysis of honey bee gene expression revealed that honey bees fed thyme oil augmented sucrose syrup had higher expression of key RNAi genes (argonaute-2 and dicer-like), antimicrobial peptide expressing genes (abaecin and hymenoptaecin), and vitellogenin, a putative honey bee health and age indicator, compared to bees fed only sucrose syrup. Virus abundance was higher in bees fed fumagillin (25 ppm or $75 \mathrm{ppm}$ ) or $1 \mathrm{ppb}$ clothianidin containing sucrose syrup relative to levels in bees fed only sucrose syrup. Whereas, honey bees fed 10 ppb clothianidin had lower virus levels, likely because consuming a near lethal dose of insecticide made them poor hosts for virus infection. The negative impact of fumagillin and clothianidin on honey bee health was indicated by the lower expression of argonaute-2, dicer-like, abaecin, and hymenoptaecin, and vitellogenin. Together, these results indicate that chemical stimulants and stressors impact the outcome of virus infection and immune gene expression in honey bees.

Keywords: honey bee, Apis mellifera, insect antiviral defense, honey bee viruses, deformed wing virus, thymol, fumagillin, clothianidin 


\section{INTRODUCTION}

Honey bees (Apis mellifera) are important pollinators of fruit, nut, and vegetable crops that make up a large proportion of the human diet (1-3). The value of pollination services in the United States is $\$ 14.6$ billion annually (4). Maintaining the honey bee pollination force has been challenging in many parts of the world, including the US, where annual colony losses averaged $38 \%$ from 2008 to 2018 (5-10). A combination of biotic and abiotic factors impact colony health including lack of quality nutritional resources, exposure to beekeeper and/or grower applied chemicals, parasites, and pathogens [reviewed in (1113)]. The ectoparasitic mite, Varroa destructor, is responsible for a large percentage of colony deaths in the US and Europe (14-16) reviewed in (17). Varroa mites feed on the bee fat bodies and hemolymph, kill brood, and vector viruses, including deformed wing virus within and between colonies (17-21). Honey bee pathogens, including bacteria, microsporidia, fungi, trypanosomatids, and viruses also contribute to honey bee colony deaths.

The largest category of honey bee infecting pathogens are positive-sense single-stranded RNA (+ssRNA) viruses [reviewed in $(22,23)]$. Honey bee infecting viruses include members of the Dicistroviridae family [e.g., Israeli acute paralysis virus (IAPV), Kashmir bee virus (KBV), acute bee paralysis virus (ABPV), and black queen cell virus (BQCV)], the Iflaviridae family [e.g., deformed wing virus (DWV), sacbrood virus (SBV)], chronic bee paralysis virus (CBPV), and the Lake Sinai viruses (LSVs) [reviewed in $(22,24)]$. DWV is one of the most well-characterized, globally distributed bee-infecting viruses $(25,26)$. In temperate climates, the prevalence and/or abundance of DWV typically increases throughout the beekeeping season (15, 27-29). High levels of DWV have been associated with honey bee colony deaths $(15,30-34)$. Honey bees infected with DWV during development may have wing deformities, whereas DWV infection in adult bees may result in asymptomatic infections or symptomatic infections characterized by shortened abdomen, cuticle discoloration, and reduced lifespan $(15,25,35,36)$. While other factors may influence the severity of virus infections, the effectiveness of honey bee antiviral defense mechanisms is the greatest determinant of the outcome of viral infection.

Honey bee immune defense mechanisms include NF- $\kappa \mathrm{B}$ mediated Toll and Imd (Immune Deficiency), Jak/STAT (Janus Kinase/Signal Transducer and Activator of Transcription), JNK (c-Jun N-terminal kinase), MAPK (Mitogen-Activated Protein Kinases), and RNA interference (RNAi) pathways [reviewed in $(22,37)]$. The antiviral role of NF- $\mathrm{\kappa B}$ mediated Toll and Imd pathways in response to specific viruses has, in part, been determined by examining the expression of antimicrobial peptide encoding genes, including abaecin and hymenoptaecin, in conjunction with quantifying virus abundance (37-41). RNA viruses produce long dsRNA molecules as they replicate within cells. These viral associated molecule patterns (VAMPS) are recognized as non-self and trigger antiviral responses. In honey bees and bumble bees dsRNA-mediated antiviral responses include both sequence-specific RNA interference (RNAi) and a non-sequence specific virus reducing response (42-47). RNAi mediated antiviral defense is initiated by the recognition of long double stranded RNAs (dsRNAs) by endoribonuclease, Dicer, which cleaves these dsRNAs into 21-23 nucleotide long small interfering RNAs (siRNAs) (48). These siRNAs are incorporated into the RNA-induced silencing complex (RISC), the non-target binding passenger strand is released, and the remaining strand in the RISC targets cognate RNAs, including viral genomes and transcripts, for Argonaute mediated cleavage, thereby lowering viral abundance (49-55). Although, the functions of these proteins have been best-characterized in other organisms, including Drosophila melanogaster $(52,55,56)$, the antiviral role of the RNAi pathway has been demonstrated in vivo in adult honey bees and larvae. Transcriptome analyses of virusinfected honey bees revealed that the expression of dicer-like and ago2 was increased in response to SINV-GFP or IAPV infection, but not in response to DWV $(34,42,43,45,57-59)$.

In addition to the immune pathways described above, the heat shock response is involved in antiviral defense in fruit flies and honey bees $(60,61)$. The heat shock response pathway is induced by various stressors including heat-stress (62). In the context of viral infection, the role of the heat shock response must be assessed for individual host-virus pairs, since heat shock proteins can both positively negatively affect viral replication (62-65). In honey bees, the expression of several heat shock protein encoding genes including heat shock protein 90 (hsp90), and heat shock $70-k D a$ protein cognate 4 (hsc70-4) are induced by SINV-GFP infection and/or heat-shock, and the expression of protein lethal (2)essential for life-like ( $p l 2)$, which encodes a protein with an Hsp20-domain, is modulated in honey bees infected with several viruses (i.e., IAPV, DWV, and SINV-GFP) $(43,57,61,66)$. Similar to the heat shock response genes, another honey bee gene that is involved in multiple functions including immunity, nutrition, stress resistance, behavioral development, ageing, oxidative stress, and longevity is vitellogenin $(v g)(67-76)$. Therefore, $v g$ expression is often utilized as a proxy for either or both honey bee age and health status [reviewed in (77)] (78-80).

Studies aimed at better characterizing the impact of viruses on honey bee health and the mechanisms of honey bee antiviral defense have involved the use of naturally-infected bees, which often have varying levels of infections, or bees experimentally inoculated with honey bee viruses (e.g., DWV, IAPV, or mixed virus stocks) or model viruses $(43,45,61,81)$. In this study, we carried out experiments using a panel of viruses. Specifically, we utilized DWV, and two model viruses [i.e., Flock House virus (FHV) and Sindbis virus tagged with green fluorescent protein (SINV-GFP)]. While it is important to carry out studies with known honey bee infecting viruses, honey bee virus preparations obtained from pupae may include co-purifying viruses, as well as other proteins, and they are not a standardized source of infectious material. The recent development of infectious clones of honey bee viruses is promising, but they have not been utilized for studies in laboratories beyond those in which they were developed (82-84).The use of model viruses circumvents the problems associated with analyzing data obtained from studies impacted by pre-existing/confounding 
infections, enables preparation of standardized viral stocks from cultured cells, and also facilitates comparative studies across different insect species. Flock House virus (FHV) naturally infects grass grubs (Costelytra zealandica), and is extensively utilized model virus that infects a wide range of other insects including mosquitoes, fruit flies, tsetse flies, and honey bees (8591). FHV has evolved a mechanism to counter the host immune response; it encodes for protein $\mathrm{B} 2$, a viral suppressor of RNAi [reviewed in (92)]. SINV-GFP is another well-characterized model virus that has been extensively utilized to investigate antiviral defense mechanisms in a wide range of insects including fruit flies, mosquitos, and honey bees (42, 43, 61, 93). SINV-GFP is easily trackable both visually using microscopy, and at the protein level via Western blot analyses. Unlike FHV, Sindbis virus does not encode a viral suppressor of RNAi (94-96). Overall, the use of a panel of viruses to examine the impact of abiotic factors on the honey bee antiviral response and the outcome of virus infection is important to ensure that results are robust and potentially generalizable.

The honey bee immune system, and in turn the outcome of virus infections in individual bees is influenced by nutritional status and environmental factors (97-100). Honey bees gather pollen and nectar from flowering plants which provision the colony with nutrients including proteins, lipids, carbohydrates, vitamins, and phytochemicals (101). In addition, honey bees gather plant resins, which are the primary component of propolis (102). Recent research efforts have focused on interaction of phytochemicals and pathogens, since plant-derived compounds can either be toxic or medicinal depending on the administered dose (103). There is precedence in the literature that honey bee diets supplemented with phytochemicals increase longevity and prime the immune system by increasing the expression of antimicrobial peptide encoding genes, for example, in honey bees fed $p$-coumaric acid, the expression of antimicrobial peptides defensin and abaecin was two-fold higher compared to control bees (104-107). For the studies described herein, we investigated the impact of phytochemical containing thyme oil on the outcome of honey bee virus infections. Honey bees forage on common thyme plants (Thymus vulgaris), which produce thymol, a phytochemical that has shown promise in reducing DWV loads in honey bees (104). Thymol, a terpene found in pollen and nectar of Thymus vulgaris, is a major component of thyme oil. T. vulgaris nectar contains 5.2 - 8.2 ppm thymol, while thymol concentrations in bee-collected pollen samples range between 0.0263 to $55.8 \mathrm{ppm}(108-110)$. Thymol has also been detected in honey (i.e., $0.27 \mathrm{ppm}$, 4 -weeks post colony treatment with 8 grams per week for 4 weeks) (111). Thyme oil contains $10 \%-64 \%$ thymol depending on the plant species, geographical sources, and harvest season, which may affect the volatile composition of the plant (112-118). Thymol is widely used as an acaricide and is an active ingredient in commercial Varroa control formulations such as Apiguard ${ }^{\circledR}$ and ApiLife VAR ${ }^{\circledR}$, which contain $25 \%$ and $74 \%$ thymol respectively $(119,120)$. Thymol treatments, ranging from $0.16 \mathrm{ppb}-120 \mathrm{ppm}$, have also shown promise in reducing levels of honey bee pathogens including Crithidia bombi, Nosema ceranae, a microsporidial/ fungal pathogen, and DWV (104, 121-124). Previous research by Palmer-Young et al., determined that newly emerged honey bees that were fed a mixture DWV and $0.16 \mathrm{ppb}$ thymol and released back in the colony, had 26-fold decrease in DWV levels 7 days post infection compared to bees exposed to DWV (104). However, in parallel studies the natural occurring DWV-levels in young bees that were maintained in laboratory and fed thymol $(0.16 \mathrm{ppb})$ for 10 days had similar DWV levels to untreated bees. This study also determined that a higher concentration of thymol (16 ppm) was toxic to honey bees. Overall, the results described by Palmer-Young et al., were intriguing, but somewhat difficult to interpret due to the lack of quantification of DWV inoculum, which was hemolymph obtained from symptomatic bees; the high degree of variation in DWV abundance in individual bees (i.e., $\Delta \mathrm{Ct}$ ranged from -20 to 12 ); and the results describing similar DWV levels in virus-inoculated bees and control bees that were not fed thymol, indicating a high level of pre-existing DWV abundance in the honey bees utilized for their studies (104).

In addition to phytochemicals, honey bees are exposed to neonicotinoid insecticides, fungicides, acaricides, and herbicides $(125,126)$. Neonicotinoids, including clothianidin, are utilized by growers to reduce the number of insects including aphids, whiteflies, leafhoppers, and planthoppers that damage crops (e.g., canola, corn, canola, cotton, soybeans) (127). Neonicotinoids are neurotoxins that disrupt the insect nervous system by irreversibly binding to nicotinic acetylcholine receptors that transmit nerve signals. This prevents signal transduction from the neurotransmitter acetylcholine, leading to paralysis and death $(128,129)$. Although honey bees are not the target insect, clothianidin is highly toxic to honey bees at doses near the median lethal dose $\left(\mathrm{LD}_{50}\right)$ of $3 \mathrm{ppb}$ for oral exposure and $22 \mathrm{ppb}$ for contact exposure (130-134). Clothianidin concentrations of up to $2.6 \mathrm{ppb}$ have been detected in pollen samples and concentrations ranging from 1 to $14 \mathrm{ppb}$, with most ranging between 0.3 to $5.4 \mathrm{ppb}$, in the nectar of treated crops $(133,135-140)$. In addition to potential lethal impact of clothianidin, sublethal doses have been shown to negatively affect honey bee immunity, grooming and hygienic behavior, neural gene expression, flight activity and homing behavior (141-152). Furthermore, honey bees exposed to pesticides including chlorpyrifos, thiamethoxam, thiacloprid, and clothianidin have greater viral loads, indicating that chemical exposure in conjunction with virus infection have a negative synergistic impact (153-157). Higher virus abundance in individual bees is in part due to dampened immune responses (154). For example, young bees exposed to clothianidin had greater DWV loads due to negative modulation of the NF- $\kappa B$ pathway (154).

Honey bee colonies are also to exposed chemicals utilized as inhive treatments against honey bee pathogens, including Nosema ceranae and Nosema apis. Nosema infections are treated at the colony level with fumagillin dicyclohexyl ammonium (i.e., Fumagilin- $\mathrm{B}^{\circledR}$ ), a compound derived from Aspergillus fumigatus (158-160). Beekeepers typically treat nosemosis with the manufacturer's recommended concentration of $25 \mathrm{ppm}$ 
fumagillin, albeit field studies have recorded the use of higher concentrations (161-164). In fact, detectable levels of fumagillin residues $(0.002 \mathrm{ppm}-0.066 \mathrm{ppm})$ persist inside the hives after treatment $(159,165)$. While fumagillin is generally considered safe for honey bee colonies, and that potential negative impacts may be negligible in comparison to nosemosis, reports of higher mortality in honey bee queens and workers fed fumagillin containing sucrose syrup led to the recommendations that bees should not be treated during the foraging season, and that treatments should be restricted to one time in the spring and fall (166-168).

To better understand the impact of a phytochemical (i.e., thymol) and agrochemicals, including a grower-applied insecticide (i.e., clothianidin) and a beekeeper applied fungicide (i.e., fumagillin), on the outcome of virus infection in honey bees, we carried out laboratory-based experiments on individual virusinfected honey bees that were fed chemical containing diets. For these studies, we utilized a panel of RNA viruses, including two model viruses FHV and SINV-GFP, and one honey bee virus, DWV. We hypothesized that thymol would act as an immunostimulant and reduce virus infection levels. In contrast, we hypothesized that virus-infected honey bees exposed to fumagillin or clothianidin would harbor more severe virus infections as a result of immunosuppressive effects. We determined that virus-infected honey bees fed thyme oil augmented sucrose syrup harbored lower virus levels, likely due to greater expression of key immune genes including dcr-like, ago2, abaecin, hymenoptaecin, and vitellogenin. Conversely, we determined that fumagillin and clothianidin exposure had a negative impact on honey bee immunocompetence with reduced expression of key immune genes including dcr-like, ago2, abaecin, hymenoptaecin, and vitellogenin, which resulted in higher virus abundance in chemical-fed bees than virus levels in bees fed only sucrose syrup. Together our results indicate that thyme oil acts as an immune stimulant and thus reduces viral burden, whereas other chemicals (i.e., fumagillin or clothianidin) negatively impact honey bee immune gene expression, and in turn result in more severe virus infections.

\section{RESULTS}

\subsection{Impact of Chemicals on Virus Infections in Honey Bees}

\subsubsection{Virus Abundance Reduced in Honey Bees Fed Thyme Oil Augmented Sucrose Syrup}

To further investigate the potential of thyme oil augmented diets to reduce viral burden, aged-matched adult bees were infected with FHV, SINV-GFP or DWV. Viruses were administered via injection, which mimicked Varroa destructor mite-mediated virus transmission and ensured that individual bees received equivalent doses. In these assays, virus-inoculated honey bees were fed $0.16 \mathrm{ppb}$ thyme oil ( $60 \mathrm{ppb}$ thymol) augmented sucrose syrup and virus abundance was assessed at 72 hpi in three independent experiments. The 72 hpi timepoint was selected since previous studies documented readily detectable levels of disseminated virus (i.e., SINV-GFP and DWV) and corresponding host immune gene expression changes at that time point $(42,43,57,61,66)$. To ensure that 72 hpi was also appropriate time to assess FHV infection levels, honey bees were inoculated with FHV ( $3.5 \times 10^{8}$ FHV RNA copies per bee), and virus abundance was quantified by RT-qPCR at 6, 48, 72, and 96 hpi (Supplemental Figure S1 and Supplemental Table S2). FHV abundance increased from 0 hpi to 72 hpi and decreased from $72 \mathrm{hpi}$ to $96 \mathrm{hpi}$. Since FHV abundance peaked at $72 \mathrm{hpi}$, this timepoint was selected to assay for FHV infection levels.

Honey bees fed sucrose syrup augmented with thyme oil harbored less virus (i.e., FHV, DWV, SINV-GFP) compared to virus-infected bees fed sucrose syrup only (Figure 1 and Supplemental Figure S2). Specifically, the total FHV abundance was $52 \%$ lower in honey bees fed thyme oil $(0.16 \mathrm{ppb})$ augmented sucrose syrup compared to bees fed sucrose syrup only ( $\mathrm{n}=10$ bees per treatment) $(p<0.001$, Wilcoxon Rank Sums test with a Benjamini-Hochberg correction for multiple comparisons) (Figure 1A). Similar levels of reduction were observed in two additional experimental replicates with $48 \%$ and $35 \%$ reduction in FHV loads respectively (Supplemental Figure S2, $p<0.001$ ). Similarly, DWV abundance was $72 \%$ lower in DWV-infected bees fed thyme oil $(0.16 \mathrm{ppb})$ augmented sucrose syrup compared to bees fed sucrose syrup only (Figure 1B, $p<0.001$ ). DWV abundance in two additional biological replicates was reduced by $48 \%$ and $25 \%$ in DWV-infected bees fed thyme oil augmented sucrose syrup compared to bees fed sucrose syrup only (Supplemental Figure S2, $p<0.01$ ). Lastly, SINV-infected bees fed thyme oil augmented sucrose syrup had $87 \%$ less virus relative to SINV-infected bees fed sucrose syrup only (Figure 1C, $p<$ 0.001 ). In two additional biological replicates of this experiment, SINV levels were reduced by $49 \%$ and $42 \%$ in SINV-infected bees fed thyme oil augmented sucrose syrup relative to bees fed sucrose syrup only (Supplemental Figure S2, $p<0.001$ ). Together these results demonstrate that virus abundance was lower when virusinfected bees were fed $0.16 \mathrm{ppb}$ thyme oil containing sucrose syrup compared to levels in bees fed non-augmented syrup and suggest that this dose of thyme oil is beneficial to honey bees.

\subsubsection{Greater Virus Abundance in Honey Bees Fed Fumagillin or Clothianidin Containing Sucrose Syrup}

To examine the potential impact of other chemicals, including a beekeeper applied fungicide and a commonly used neonicotinoid insecticide on the outcome of virus infections, virus-infected honey bees were fed sucrose syrup containing fumagillin and clothianidin. Specifically, virus-infected honey bees were fed sucrose syrup containing $25 \mathrm{ppm}$ or $75 \mathrm{ppm}$ fumagillin, or a sublethal (1 ppb) or a near lethal dose $(10 \mathrm{ppb})$ of clothianidin, and virus abundance was quantified at $72 \mathrm{hpi}$. We hypothesized that virus abundance would be greater in bees exposed to virus infection and chemical exposure. We determined that, in general, virus abundance was greater in honey bees that were exposed to chemicals in their diet. Specifically, FHV abundance in bees fed sucrose syrup containing $25 \mathrm{ppm}$ or $75 \mathrm{ppm}$ fumagillin was $15 \%$ $(p=0.006)$ and $30 \%$ higher $(p<0.001)$, respectively (Figure 2A). FHV-infected bees fed clothianidin (1 ppb) containing sucrose syrup had $94 \%$ more FHV relative to sucrose syrup fed bees $(p<$ 
A

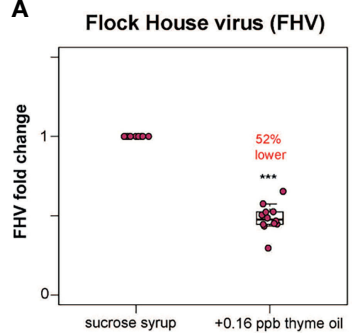

B

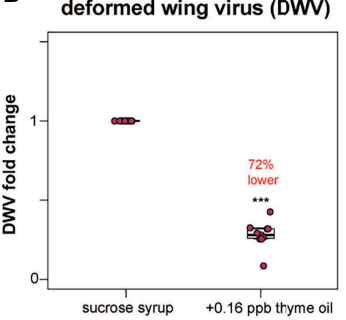

C

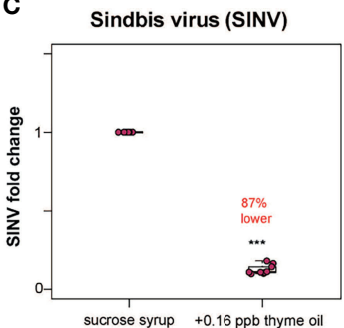

FIGURE 1 | Lower virus abundance in honey bees fed thyme oil augmented sucrose syrup. Virus abundance in individual honey bees that were either fed sucrose syrup only or sucrose syrup augmented with $0.16 \mathrm{ppb}$ thyme oil was assessed at $72 \mathrm{~h}$ post-infection by $\mathrm{gPCR}(\mathrm{n}=9-12$ per treatment group) and the relative virus abundance is presented as ranked fold-changes. Together, these data illustrate that virus-infected bees fed thyme oil augmented sucrose syrup harbored less virus than virus-infected bees fed only sucrose syrup. (A) Flock House virus (FHV)-infected bees fed sucrose syrup augmented with thyme oil (0.16 ppb) had $52 \%$ less FHV (0.48 mean fold change) than bees fed sucrose syrup alone $\left(p=2.1 \times 10^{-5}\right)$. (B) In deformed wing virus (DWV)-infected bees, virus abundance was $72 \%$ less in bees fed sucrose syrup augmented with thyme oil (0.28 mean fold change) compared to bees fed only sucrose syrup ( $p=0.00016)$. (C) Sindbis virus (SINV)-infected bees fed thyme oil augmented sucrose syrup had $87 \%$ less SINV ( 0.13 mean fold change) than bees fed sucrose syrup. Data were analyzed by a pairwise Wilcoxon Rank Sums with a Benjamini-Hochberg correction for multiple comparisons. Asterisks indicate a significant difference in virus abundance; significance levels: ${ }^{\star \star \star} p<$ 0.0005. This figure includes results from one representative biological replicate for each virus (i.e., rep1). The data for all three biological replicates are presented in Supplemental Figure $\mathbf{S 2}$ and raw data are in Supplemental Tables S3, S4.

0.001 ), whereas unexpectedly virus abundance was reduced by $15 \%$ in FHV-infected bees fed sucrose syrup containing $10 \mathrm{ppb}$ clothianidin relative to FHV-infected bees fed sucrose syrup only $(p<0.001)$ (Figure 2A). Similarly, in DWV-infected bees, virus abundance was $53 \%$ higher in bees fed sucrose syrup containing 25 ppm fumagillin $(p<0.001), 11 \%$ higher in bees fed 75 ppm fumagillin sucrose syrup ( $p<0.01$ ), and $291 \%$ higher in bees fed $1 \mathrm{ppb}$ clothianidin containing sucrose syrup $(p<0.001)$ (Figure 2B). DWV abundance was $21 \%$ lower in DWVinfected bees fed $10 \mathrm{ppb}$ clothianidin containing sucrose syrup compared to DWV-infected bees fed sucrose syrup only ( $p=$ 0.04) (Figure 2B). Honey bees infected with SINV and fed 25

\section{A}

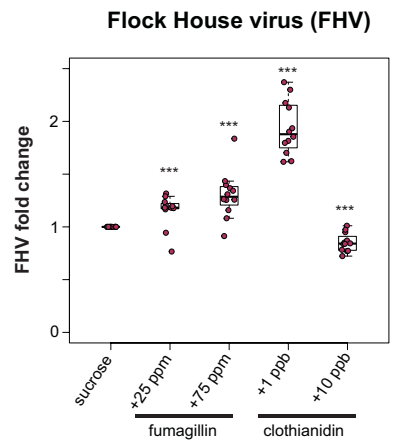

B

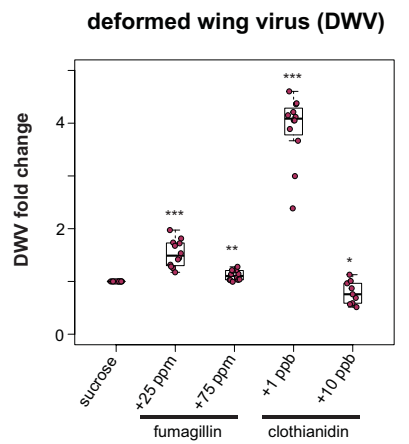

C

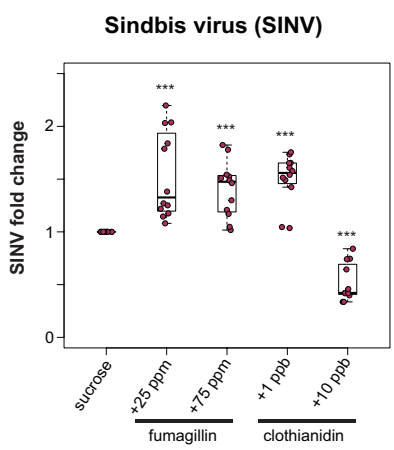

FIGURE 2 | Honey bees fed sucrose syrup containing fumagillin or clothianidin had greater virus levels than bees feed only sucrose syrup. Virus abundance in individual honey bees that were either fed sucrose syrup only or fungicide or insecticide containing sucrose syrup was assessed at $72 \mathrm{~h}$ post-infection by qPCR $(\mathrm{n}=9-12 \mathrm{per}$ treatment group) and the relative virus abundance is presented as ranked fold-changes. Data from virus infected honey bees fed sucrose syrup mixed with fumagillin (25 ppm or $75 \mathrm{ppm}$ ) or clothianidin (1 ppb or $10 \mathrm{ppb)} \mathrm{illustrate} \mathrm{that} \mathrm{bees} \mathrm{fed} \mathrm{sucrose} \mathrm{syrup} \mathrm{containing} 25$ ppm fumagillin, 75 ppm fumagillin, and 1 ppb clothianidin harbored more virus than virus-infected bees fed sucrose syrup only, whereas bees fed sucrose syrup containing 10 ppb clothianidin had lower virus levels (A) Flock House virus (FHV)-infected bees fed $25 \mathrm{ppm}$ fumagillin $(p=0.006), 75 \mathrm{ppm}$ fumagillin $(p=0.0009)$ or $1 \mathrm{ppb}$ clothianidin $\left(p=8.2 \times 10^{-5}\right)$ containing sucrose syrup had greater virus levels than bees fed sucrose only syrup. Whereas, FHV-infected bees fed sucrose syrup containing $10 \mathrm{ppb}$ clothianidin had lower virus levels than bees fed only sucrose $\operatorname{syrup}\left(p=0.0009\right.$ ). (B) Deformed wing virus (DW)-infected bees fed sucrose syrup containing $25 \mathrm{ppm}$ fumagillin $\left(p=8.2 \times 10^{-5}\right), 75$ ppm fumagillin $(p=0.0022)$ or 1 ppb clothianidin $\left(p=8.2 \times 10^{-5}\right)$ harbored more virus than DW-infected bees fed only sucrose syrup. DWV-infected bees fed 10 ppb clothianidin containing sucrose syrup had less virus compared to bees fed sucrose syrup $(p=0.04)$. (C) Sindbis virus (SINV) abundance was higher in bees fed sucrose syrup containing 25 ppm fumagillin $\left(p=6.2 \times 10^{-5}\right), 75 \mathrm{ppm}$ fumagillin $\left(p=6.2 \times 10^{-5}\right)$ or $1 \mathrm{ppb}$ clothianidin $\left(p=6.2 \times 10^{-5}\right)$ compared to SINV-infected bees fed only sucrose syrup. In contrast, SINV-infected bees fed sucrose syrup containing $10 \mathrm{ppb}$ clothianidin had lower levels of virus infection than bees fed sucrose only syrup $\left(p=6.8 \times 10^{-5}\right)$. Data were analyzed by a pairwise Wilcoxon Rank Sums with a Benjamini-Hochberg correction for multiple comparisons. Asterisks indicate a significant change in virus abundance; significance levels: ${ }^{*} p<0.05 ;{ }^{* *} p<0.005 ;{ }^{* \star *} p<0.0005$. This figure includes results from one representative biological replicate for each virus (i.e., rep3). The data for all three biological replicates are presented in Supplemental Figure S3. Raw data are included in Supplemental Tables S5, S6. 
ppm fumagillin containing sucrose syrup harbored 53\% more virus $(p<0.001)$, SINV-infected bees fed $75 \mathrm{ppm}$ fumagillin containing sucrose syrup harbored $41 \%$ more virus $(p<0.001)$, while SINV infected bees fed 1 ppb clothianidin containing sucrose syrup had $50 \%$ more virus relative to sucrose only $(p<$ 0.001). SINV-infected bees fed $10 \mathrm{ppb}$ clothianidin containing sucrose syrup harbored $48 \%$ less SINV compared to bees fed sucrose syrup only $(p<0.001)$ (Figure 2C). Data obtained from two additional biological replicates resulted in similar changes in virus abundance when virus-infected bees (i.e., FHV, DWV, or SINV-GFP) were fed sucrose syrup containing fumagillin or clothianidin (Supplemental Figure S3, $p<0.05$ ). Together these data indicate that virus-infected bees fed recommended (25 ppm) or higher (75 ppm) doses of fumagillin or $1 \mathrm{ppb}$ clothianidin had greater viral loads, whereas bees fed $10 \mathrm{ppb}$ clothianidin in sucrose syrup ad libitum had slightly lower virus levels at $72 \mathrm{hpi}$. This may be indicative of the poor overall health status of the host to support virus replication.

\subsection{Impact of Chemicals on Honey Bee Immune Gene Expression \\ 2.2.1 Expression of Key RNAi Genes Is Higher in Thyme Oil Fed Bees, Reduced in Fumagillin and Clothianidin Fed Honey Bees}

To investigate whether the changes in virus abundance in honey bees fed sucrose syrup containing additives were reflective of modulations in the expression of key RNAi genes, the expression of argonaute-2 (ago2) and dicer-like (dcr) were assessed at $72 \mathrm{hpi}$. In general, the expression of dcr-like and ago 2 were higher in virus-infected honey bees fed thyme oil containing sucrose syrup, and modestly reduced in virusinfected honey bees fed fumagillin or clothianidin containing sucrose syrup (Figure 3). Specifically, FHV-infected bees fed thyme oil exhibited 1.57 fold $(p<0.001)$ higher dcr-like expression and 1.23 fold higher ago2 expression, compared to virus-infected bees fed sucrose syrup only $(p=0.001)$. Whereas FHV-infected bees fed sucrose syrup containing either 25 ppm or $75 \mathrm{ppm}$ fumagillin exhibited reduced expression of $d c r$-like (i.e., 0.40 fold, $p=0.006$, and 0.34 fold, $p<0.001$, respectively) and $a g o 2$ (i.e., 0.82 fold, $p=0.002$ and 0.69 fold, $p<0.001$, respectively). Similarly, FHV-infected bees fed clothianidin containing sucrose syrup expressed less $d c r$-like (i.e., $1 \mathrm{ppb}-0.81$ fold, $p<0.001$ and $10 \mathrm{ppb}-0.49$ fold, $p=0.0031$ ) and ago 2 (i.e., $1 \mathrm{ppb}-0.86$ fold, $p=$ 0.023 and $10 \mathrm{ppb}-0.74$ fold, $p<0.01$ ) (Figure 3). These results were consistent in two additional biological replicates of this experiment (Supplemental Figure S4, $p<0.05$ ) except, in rep2, ago 2 expression in $\mathrm{FHV}$-infected bees fed $1 \mathrm{ppb}$ clothianidin was not reduced.

DWV-infected bees fed thyme oil (0.16 ppb) augmented sucrose syrup had 1.66 fold higher $d c r$-like expression relative to DWV-infected bees fed sucrose syrup only $(p<0.001)$. However, dcr-like expression in DWV-infected bees fed fumagillin was reduced (i.e., $25 \mathrm{ppm}-0.58$ fold, $p<0.001$ and 75 ppm - 0.49 fold, $p<0.001)$. A reduction in dcr-like expression was also observed in DWV-infected bees fed $1 \mathrm{ppb}$ clothianidin (0.67 fold, $p=0.04$ ), but $d c r$-like expression levels were not changed in bees fed $10 \mathrm{ppb}$ clothianidin containing sucrose syrup (Figure 3A). The expression of ago2 in DWV-infected bees fed thyme oil containing sucrose followed a similar trend with 1.16 fold higher expression $(p=0.035)$, and reduced expression in bees fed sucrose syrup containing $25 \mathrm{ppm}$ fumagillin ( 0.72 fold, $p$ $=0.024), 75 \mathrm{ppm}$ fumagillin (0.43 fold, $p<0.001)$, and $1 \mathrm{ppb}$ clothianidin ( 0.81 fold, $p<0.001)$, whereas ago 2 expression was not changed in DWV-infected bees fed sucrose syrup containing $10 \mathrm{ppb}$ clothianidin (Figure 3B). These results were consistent in two additional biological replicates of this experiment (Supplemental Figures S4, S5, $p<0.05$ ).

Comparably, SINV-infected bees fed thyme oil augmented sucrose syrup had higher levels of $d c r$-like expression than SINVinfected bees fed sucrose syrup only (i.e., 1.68 fold, $p<0.001$ ) (Figure 3A). Whereas the combination of virus infection and chemical exposure resulted in reduced $d c r$-like expression (i.e., in SINV-infected bees fed $25 \mathrm{ppm}$ fumagillin ( 0.81 fold, $p=0.014)$, $75 \mathrm{ppm}$ fumagillin ( 0.66 fold, $p=0.018), 1 \mathrm{ppb}$ clothianidin $(0.74$ fold, $p<0.01$ ), and $10 \mathrm{ppb}$ clothianidin containing sucrose syrup (0.79 fold, $p<0.001$ ) compared to SINV-infected bees fed sucrose syrup only) (Figure 3A). Likewise, SINV-infected bees fed thyme oil containing sucrose syrup had 1.17 fold higher ago 2 expression $(p=0.002)$, whereas expression was slightly lower in bees fed sucrose syrup containing $25 \mathrm{ppm}$ fumagillin 0.77 fold, ( $p<0.001), 75 \mathrm{ppm}$ fumagillin (0.75 fold, $p<0.001), 1 \mathrm{ppb}$ clothianidin ( 0.9 fold, $p<0.01)$, and $10 \mathrm{ppb}$ clothianidin $(0.89$ fold, $p=0.002$ ) (Figure 3B). The majority of these results were consistent in two additional biological replicates of this experiment (Supplemental Figures S4, S5, $p<0.05$ ) except dcr-like expression in SINV-infected bees fed $10 \mathrm{ppb}$ clothianidin in rep3, and ago2 expression in SINV-infected bees fed $25 \mathrm{ppm}$ fumagillin in rep2 were similar to expression levels in virusinfected bees fed only sucrose syrup $(p>0.05)$. Together these results demonstrate that the expression of $d c r$-like and ago 2 were greater in virus-infected honey bees fed thyme oil (0.16 ppb) containing sucrose syrup, whereas expression of these genes was modestly reduced in virus-infected bees fed pesticide containing sucrose syrup.

To disentangle the gene expression results obtained from honey bees simultaneously impacted by two stressors (i.e., virus-infection and oral exposure to chemicals), gene expression was measured in non-virus infected honey bees (i.e., mock-infected). These analyses determined that the expression of both $d c r$-like and ago 2 were higher in thyme oil fed bees by 1.86 fold and 1.75 fold higher respectively $(p<$ 0.001 ) (Figure 3). Whereas the expression of dcr-like and ago 2 in bees fed fumagillin or clothianidin was reduced, albeit to a lesser degree compared to the increase observed with thyme oil (Figure 3). Specifically, mock-infected bees fed fumagillin in sucrose at $25 \mathrm{ppm}$ and $75 \mathrm{ppm}$ concentrations had 0.77 fold ( $p$ $<0.001)$ and 0.77 fold lower $d c r$-like expression levels $(p<$ $0.001)$, and 0.59 fold $(p<0.001)$, and no appreciable change in ago 2 expression, respectively. Likewise, mock-infected bees fed clothianidin in sucrose syrup at $1 \mathrm{ppb}$ and $10 \mathrm{ppb}$ concentrations had 0.75 fold $(p<0.01)$ and 0.72 fold $(p<$ $0.001)$ dcr-like expression levels, and 0.69 fold $(p<0.001)$ and 0.81 fold $(p<0.001)$ ago 2 expression levels, respectively. 

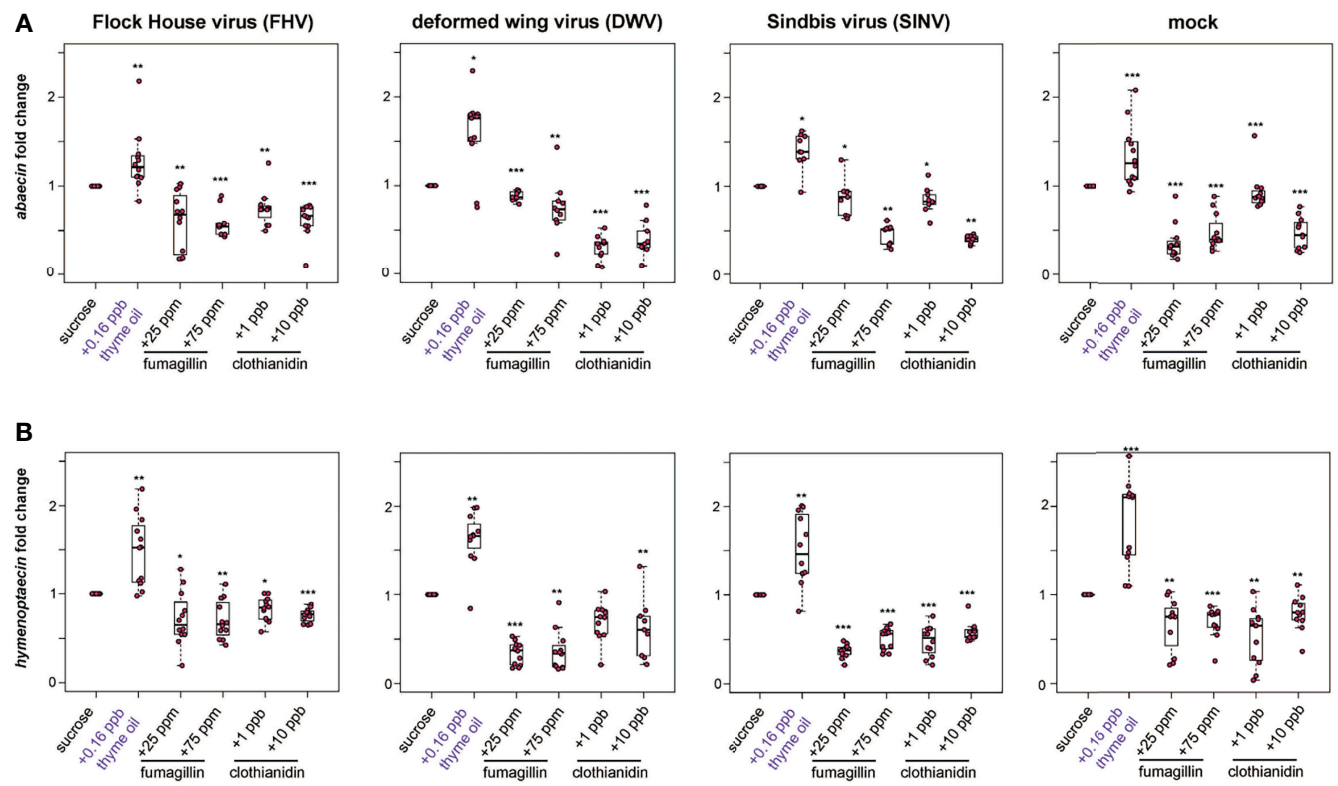

FIGURE 3 | Expression of key RNAi genes was higher in honey bees fed thyme oil augmented sucrose syrup and lower in bees fed sucrose syrup containing fumagillin or clothianidin. Expression of dicer-like and argonaute-2 in honey bees that were either mock- or virus-infected (i.e., FHV, DWV, SINV) and fed sucrose syrup only or syrup containing either thyme oil $(0.16 \mathrm{ppb})$, fumagillin ( $25 \mathrm{ppm}$ or $75 \mathrm{ppm}$ ), or clothianidin (1 ppb or $10 \mathrm{ppb})$ was assessed by qPCR. The $\Delta \Delta \mathrm{Ct}$ method with normalization to rp/8 in mock or virus-infected bees fed sucrose syrup diet was utilized to determine the relative gene expression. (A) Dicer-like (dcr-like) expression was higher in virus-infected (i.e., FHV, DWV, SINV) and mock-infected bees fed thyme oil containing sucrose syrup, and lower in bees fed sucrose syrup containing fumagillin (25 ppm or 75 ppm) or clothianidin (1 ppb or 10 ppb) relative to bees fed sucrose syrup. (B) Argonaute-2 (ago2) expression was higher in virusinfected (i.e., FHV, DWV, SINV) or mock-infected bees fed thyme oil augmented sucrose syrup and reduced in bees fed diets containing fumagillin (25 ppm or 75 ppm) or clothianidin (1 ppb or 10 ppb), except in mock-infected bees fed 75 ppm fumagillin, ago 2 expression was similar to expression levels in bees fed sucrose only. Data were analyzed by a pairwise Wilcoxon Rank Sums with a Benjamini-Hochberg correction for multiple comparisons. Asterisks indicate a significant change in gene expression compared to sucrose only control; significance levels: ${ }^{*} p<0.05 ;{ }^{* *} p<0.005 ;{ }^{* * *} p<0.0005$. This figure shows representative biological replicate for each gene (i.e., rep2 for dcr-like and rep3 for ago2). The data for all three biological replicates are presented in Supplemental Figures S4, S5. Raw data are included in Supplemental Tables S7-S10.

\subsubsection{Expression of Heat Shock Protein Encoding Genes Is Higher in Thyme Oil, Fumagillin, and Clothianidin Fed Honey Bees}

The heat shock response may be induced by a variety of stressors; therefore, we examined the expression of a subset of heat shock response genes (i.e., $p l 2, h s p 90$, and $h s c 70-4$ ) in the context of virus infection and/or chemical exposure. In general, the expression of heat shock protein encoding genes was higher in virus and mock-infected bees fed sucrose syrup containing thyme oil (0.16 ppb), fumagillin (25 ppm or $75 \mathrm{ppm}$ ) or clothianidin (1 ppb or $10 \mathrm{ppb}$ ), indicating that the expression of these genes is also induced in response to chemical stressors (Figure 4 and Supplemental Figure S6).

In this study, $p l 2$ exhibited the highest induction in response to virus-infection (i.e., FHV, DWV, and SINV) and chemical stress (Figure 4A). In FHV-infected bees, pl2 expression in bees fed thyme oil augmented sucrose syrup was similar to bees fed non-augmented sucrose syrup, but $p l 2$ expression was greater in bees that ingested sucrose syrup containing $25 \mathrm{ppm}$ fumagillin (1.42 fold, $p<0.001$ ), 75 ppm fumagillin (2.26 fold, $p<0.001$ ), 1 ppb clothianidin (2.69 fold, $p<0.001)$, and $10 \mathrm{ppb}$ clothianidin (1.55 fold, $p<0.01$ ) compared to FHV-infected bees fed only sucrose syrup. Similarly, DWV-infected bees exhibited higher pl2 expression when fed sucrose syrup containing $0.16 \mathrm{ppb}$ thyme oil (3.32 fold, $p<0.001$ ), 25 ppm fumagillin (2.7 fold, $p<0.001$ ), 75 ppm fumagillin (2.65 fold, $p<0.001$ ), 1 ppb clothianidin (1.69 fold, $p<0.001$ ), and $10 \mathrm{ppb}$ clothianidin (3.74 fold, $p<0.001$ ) relative to DWV-infected bees fed sucrose syrup only (Figure 4A). In SINV-infected bees, pl2 expression was higher in bees fed sucrose syrup containing thyme oil ( 2.3 fold, $p<0.01$ ), $25 \mathrm{ppm}$ fumagillin (3.63 fold, $p<0.01), 75 \mathrm{ppm}$ fumagillin $(4.57$ fold, $p<0.01$ ), $1 \mathrm{ppb}$ clothianidin (3.97 fold, $p=0.023$ ), and 10 ppb clothianidin (3.58 fold, $p<0.01$ ) compared to bees fed sucrose syrup only (Figure 4A). The expression level of $p l 2$ was higher in mock-infected bees fed sucrose syrup containing 25 ppm fumagillin (1.27 fold, $p<0.001), 75$ ppm fumagillin $(1.35$ fold, $p<0.01)$, and $1 \mathrm{ppb}$ clothianidin $(2.04$ fold, $p<0.001)$ relative to sucrose only fed bees (Figure $4 \mathbf{A}$ ). Whereas pl2 expression in mock-infected bees fed sucrose syrup containing thyme oil or $10 \mathrm{ppb}$ clothianidin was similar to levels in mockinfected bees fed only sucrose syrup $(p>0.05)$. In two additional biological replicates, $p l 2$ expression was greater in virus or mockinfected bees fed sucrose syrup containing thyme oil (0.16 ppb), fumagillin (25 ppm or $75 \mathrm{ppm}$ ) or clothianidin (1 ppb or $10 \mathrm{ppb})$, 
except in a few treatment groups that exhibited pl2 levels similar to those observed in honey bees fed sucrose syrup alone [i.e., in rep2, DWV-infected bees fed 25 ppm fumagillin; in rep3, FHVinfected bees fed $0.16 \mathrm{ppb}$ thyme oil augmented sucrose syrup and DWV-infected bees fed 75 ppm fumagillin containing sucrose syrup (Supplemental Figure S6)].

The expression of heat shock protein 90 (hsp90), which encodes a protein chaperone that is involved in RISC assembly and siRNA loading, was greater in several treatment groups (169, 170) (Figure 4). Specifically, $h s p 90$ expression was higher in FHV-infected bees fed sucrose syrup containing thyme oil (1.26 fold, $p=0.037$ ), $25 \mathrm{ppm}$ fumagillin (1.36 fold, $p<0.001$ ), $75 \mathrm{ppm}$ fumagillin (1.54 fold, $p<0.001$ ), 1 ppb clothianidin ( 1.5 fold, $p=$ $0.004)$, and $10 \mathrm{ppb}$ clothianidin (1.26 fold, $p=0.003$ ) compared to expression levels in bees fed only sucrose syrup (Figure $4 \mathbf{B}$ ). Likewise, the expression of $h s p 90$ in DWV-infected bees was higher in bees fed sucrose syrup containing thyme oil (1.38 fold, $p<0.001), 25 \mathrm{ppm}$ fumagillin (2.02 fold, $p<0.001), 75 \mathrm{ppm}$ fumagillin (1.49 fold, $p<0.001$ ), 1 ppb clothianidin (1.63 fold, $p<$ 0.001 ), and $10 \mathrm{ppb}$ clothianidin ( 1.33 fold, $p<0.001$ ), relative to sucrose syrup fed bees (Figure 4B). While in SINV-infected bees fed sucrose syrup augmented with $0.16 \mathrm{ppb}$ thyme oil, hsp90
A

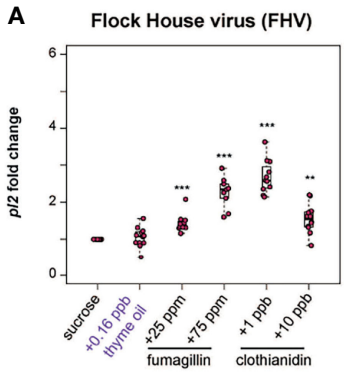

B

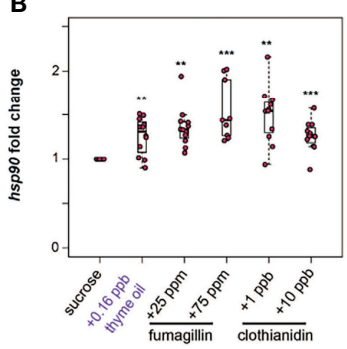

C

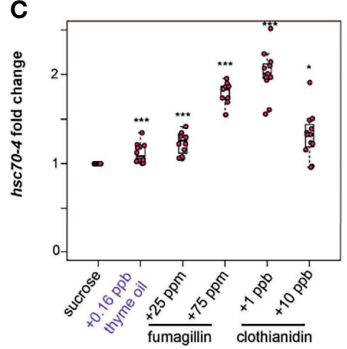

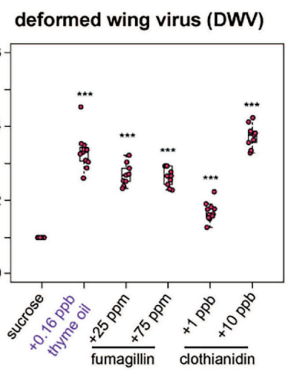
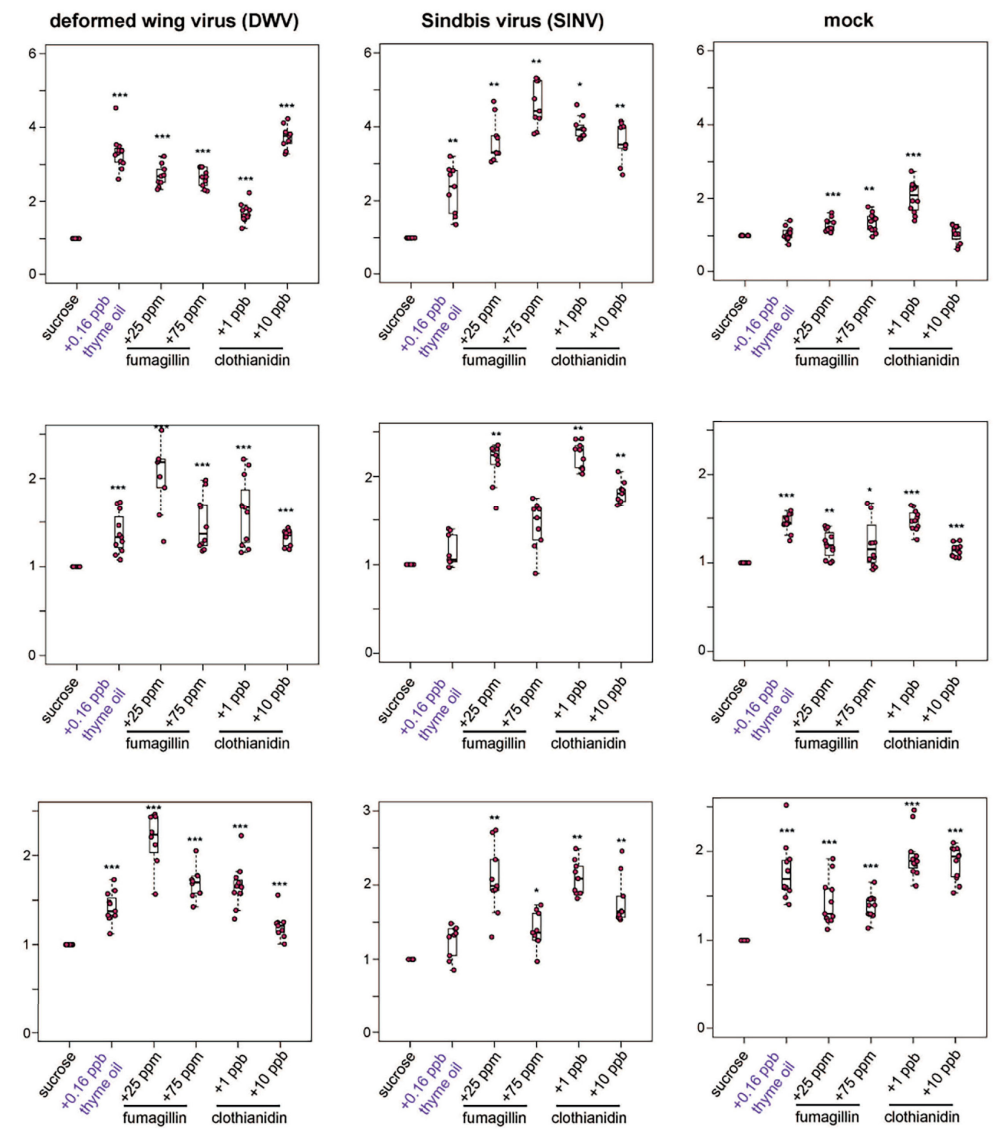

FIGURE 4 | Expression of heat shock protein encoding genes was higher in honey bees fed sucrose syrup containing thyme oil, fumagillin, or clothianidin. The relative expression of three genes encoding heat shock proteins (p/2, hsp90, hsc70-4) was assessed using qPCR in mock or virus-infected bees fed sucrose syrup only or sucrose syrup containing additivities (i.e., thyme oil, fumagillin, or clothianidin). The $\Delta \Delta \mathrm{Ct}$ method with normalization to rp/8 in mock or virus-infected bees fed sucrose syrup diet was utilized to determine the relative gene expression. (A) Protein lethal(2)essential for life-like (p/2) expression in virus-infected bees (i.e., FHV, DWV, SINV) fed sucrose syrup containing thyme oil, fumagillin (25 ppm or 75 ppm) or clothianidin (1 ppb or 10 ppb) was higher compared to expression in bees fed sucrose only. In mock-infected bees, pl2 expression in bees fed sucrose syrup containing stimulant (0.16 ppb thyme oil) or 10 ppb clothianidin was similar to expression levels in bees fed sucrose only, whereas p/2 expression was higher in bees fed sucrose syrup containing fumagillin (25 ppm or 75 ppm) or 1 ppb clothianidin. (B) Heat shock protein 90 (hsp90) expression was higher in majority of the treatment groups, including virus- or mock-infected infected bees fed augmented sucrose syrups compared to bees fed non-augmented sucrose syrup except in SINV-infected bees fed thyme oil or 75 ppm fumagillin, which had similar hsp90 expression levels to bees fed sucrose only. (C) Heat shock 70-kDa protein cognate 4 (hsc70-4) expression was higher in the majority of treatment groups including mock and virus-infected bees fed sucrose syrup containing either thyme oil (0.16 ppb), fumagillin (25 ppm or 75 ppm) or clothianidin (1 ppb or 10 ppb), except in SINV-infected bees fed sucrose syrup containing thyme oil, which had hsc70-4 expression levels similar to the controls. Data were analyzed by a pairwise Wilcoxon Rank Sums with a Benjamini-Hochberg correction for multiple comparisons. Asterisks indicate a significant change in gene expression compared to sucrose only control; significance levels: ${ }^{\star} p<0.05$; ${ }^{* *} p<0.005 ;{ }^{* \star *} p<0.0005$. This figure shows representative biological replicate for $p / 2$ expression (i.e., rep1). The data for all three biological replicates for p/2 are presented in Supplemental Figure S6 and raw data are included in Supplemental Tables S11-S16. 
expression was similar to bees fed only sucrose syrup. The expression of $h s p 90$ was higher in SINV-infected bees fed sucrose syrup containing $25 \mathrm{ppm}$ fumagillin (2.15 fold, $p=$ 0.001), 75 ppm fumagillin (1.44 fold, $p=0.017), 1 \mathrm{ppb}$ clothianidin ( 2.24 fold, $p=0.001)$, and $10 \mathrm{ppb}$ clothianidin (1.81 fold, $p=0.001$ ), relative to sucrose syrup fed bees (Figure 4B). Expression of $h s p 90$ was also greater in mockinfected bees fed sucrose syrup containing thyme oil (1.45 fold, $p<0.001), 25 \mathrm{ppm}$ fumagillin (1.2 fold, $p=0.001$ ), $75 \mathrm{ppm}$ fumagillin (1.31 fold, $p=0.017$ ), 1 ppb clothianidin (1.48 fold, $p<$ 0.001 ), and $10 \mathrm{ppb}$ clothianidin (1.14 fold, $p<0.001$ ), compared to sucrose syrup fed bees (Figure 4B).

Heat shock protein $70 \mathrm{kDa}$ cognate 4 (hsc70-4) is a constitutively expressed molecular chaperone and functions with the cooperation of co-chaperones. It is involved in RISC assembly and maintenance of cellular protein homeostasis, including protein folding, assembly, disassembly, and degradation (171-173). Expression of $h s c 70-4$ was higher in FHV-infected bees fed sucrose syrup containing thyme oil (1.12 fold, $p<0.001$ ), 25 ppm fumagillin (1.23 fold, $p<0.001$ ), $75 \mathrm{ppm}$ fumagillin (1.79 fold, $p<0.001$ ), 1 ppb clothianidin (2.01 fold, $p<$ $0.001)$, and $10 \mathrm{ppb}$ clothianidin (1.32 fold, $p=0.016)$ relative to sucrose syrup fed bees (Figure 4C). DWV-infected bees fed sucrose syrup containing either stimulant (thyme oil) or stressors (fumagillin or clothianidin) exhibited greater $h s c 70-4$ expression than bees fed sucrose syrup only i.e., thyme oil- 1.42 fold; 25 ppm fumagillin- 2 fold; 75 ppm fumagillin- 1.69 fold; 1 ppb clothianidin- 1.65 fold; and 10 ppb clothianidin- 1.21 fold ( $p<$ 0.001) (Figure 4C). While SINV-infected bees fed thyme oil augmented sucrose syrup had similar $h s c 70-4$ expression relative to SINV-infected bees fed only sucrose syrup, SINV-infected bees fed chemical stressors exhibited greater $h s c 70-4$ expression i.e., 25 ppm fumagillin (2.07 fold, $p=0.001$ ), 75 ppm fumagillin (1.4 fold, $p=0.024), 1 \mathrm{ppb}$ clothianidin (2.1 fold, $p=0.001)$, and $10 \mathrm{ppb}$ clothianidin ( 1.79 fold, $p=0.001$ ) (Figure 4C). Hsc70-4 expression was greater in mock-infected honey bees fed either augmented diets, compared to those fed only sucrose syrup i.e., thyme oil1.76 fold; 25 ppm fumagillin- 1.5 fold; 75 ppm fumagillin- 1.39 fold; 1 ppb clothianidin- 1.94 fold; and 10 ppb clothianidin- 1.87 fold relative to sucrose syrup fed bees $(p<0.001)$ (Figure 4C). Since analyses of $h s p 90$ and $h s c 70-4$ expression in one biological replicate was similar to $p l 2$ expression data indicating that in general honey bee heat shock protein encoding genes exhibited higher expression in response to all chemicals, including thyme oil, fumagillin, and clothianidin, additional biological replicates were not analyzed for $h s p 90$ and $h s c 70-4$ expression.

\subsubsection{Greater Expression of Antimicrobial Peptide Encoding Genes in Thyme Oil Fed Bees, Reduced in Fumagillin and Clothianidin Fed Bees}

The honey bee genome encodes a suite of antimicrobial proteins (AMPs) that are expressed in response to microbial pathogens. Although the role of these genes in the context of virus infections in insects has not been well-characterized, increased expression is commonly used as a hallmark of active immune signaling pathways including the Toll, Imd, and Jak/STAT pathways [reviewed in $(37,40,41)]$. Therefore, we examined the expression of two honey bee AMP encoding genes abaecin and hymenoptaecin as an indicator of immune pathway status in virus-infected bees fed chemically augmented sucrose syrup. Abaecin is an effector molecule expressed as a result of an immune challenge that triggers the induction of Toll and Imd pathways (174-176). Abaecin expression in FHV-infected honey bees fed sucrose syrup supplemented with thyme oil was 1.28 fold higher relative to those fed only sucrose syrup $(p=0.001)$ (Figure 5A). In contrast, abaecin expression in FHV-infected bees fed either fumagillin or clothianidin was slightly lower than expression in FHV-infected bees fed plain sucrose syrup (i.e., 25 ppm fumagillin, 0.61 fold, $p=0.001 ; 75 \mathrm{ppm}$ fumagillin, 0.59 fold, $p<0.001 ; 1 \mathrm{ppb}$ clothianidin, 0.75 fold, $p=0.002$; and 10 ppb clothianidin, 0.63 fold, $p<0.001$ ) (Figure 5A). DWVinfected bees fed thyme oil augmented sucrose syrup had 1.58 fold greater abaecin expression than sucrose syrup fed bees ( $p=$ 0.029). Whereas chemically stressed DWV-infected bees exhibited reduced abaecin expression than DWV-infected bees fed sucrose syrup alone (i.e., 25 ppm fumagillin, 0.88 fold, $p<$ $0.001 ; 75$ ppm fumagillin, 0.76 fold, $p=0.003 ; 1 \mathrm{ppb}$ clothianidin, 0.3 fold, $p<0.001$; and 10 ppb clothianidin, 0.4 fold, $p<0.001$ ) (Figure 5A). Likewise, SINV-infected honey bees fed thyme oil augmented sucrose syrup had 1.4 fold higher abaecin expression compared to sucrose syrup fed bees $(p=0.01)$. Whereas SINVinfected bees fed chemical stressors exhibited reduced abaecin expression (i.e., $25 \mathrm{ppm}$ fumagillin, 0.87 fold, $p=0.01 ; 75 \mathrm{ppm}$ fumagillin, 0.45 fold, $p=0.001 ; 1 \mathrm{ppb}$ clothianidin, 0.85 fold, $p=$ 0.01 ; and $10 \mathrm{ppb}$ clothianidin, 0.41 fold, $p=0.001$ ) (Figure 5A). The same trend was also observed in mock-infected bees, which exhibited 1.33 fold higher abaecin expression in bees fed thyme oil augmented sucrose syrup compared to levels in bees fed nonaugmented sucrose syrup $(p<0.001)$. Whereas abaecin expression was reduced in mock-infected bees fed sucrose syrup containing 25 ppm fumagillin ( 0.36 fold, $p<0.001), 75$ ppm fumagillin ( 0.47 fold, $p<0.001), 1$ ppb clothianidin $(0.92$ fold, $p<0.001$ ), and 10 ppb clothianidin ( 0.47 fold, $p<0.001$ ) (Figure 5A). In general, similar trends in abaecin expression was observed in one additional biological replicate except abaecin expression in FHV-infected bees fed sucrose syrup containing 75 ppm fumagillin or DWV-infected bees fed $1 \mathrm{ppb}$ clothianidin was similar to expression levels in bees fed sucrose syrup (Supplemental Figure S7, $p>0.05$ ).

Hymenoptaecin is an antimicrobial peptide encoding gene that is induced via the nuclear factor kappa B (NF- $\mathrm{BB})$ signaling in Imd pathway (175). In the previous study by Palmer-Young et al., expression of hymenoptaecin in laboratory contained bees fed $0.16 \mathrm{ppb}$ thymol for 7 days exhibited 12.9 to 61 -fold greater expression than control bees (104). In our study, the overall trend in hymenoptaecin expression in bees that were either mock- or virus-infected and fed sucrose syrup containing thyme oil was higher, whereas in bees fed fumagillin, or clothianidin were lower relative to bees fed sucrose syrup (Figure 5B). FHV-infected bees fed thyme oil containing sucrose syrup had 1.48 fold higher expression of hymenoptaecin compared to bees fed sucrose syrup $(p=0.002)$. 

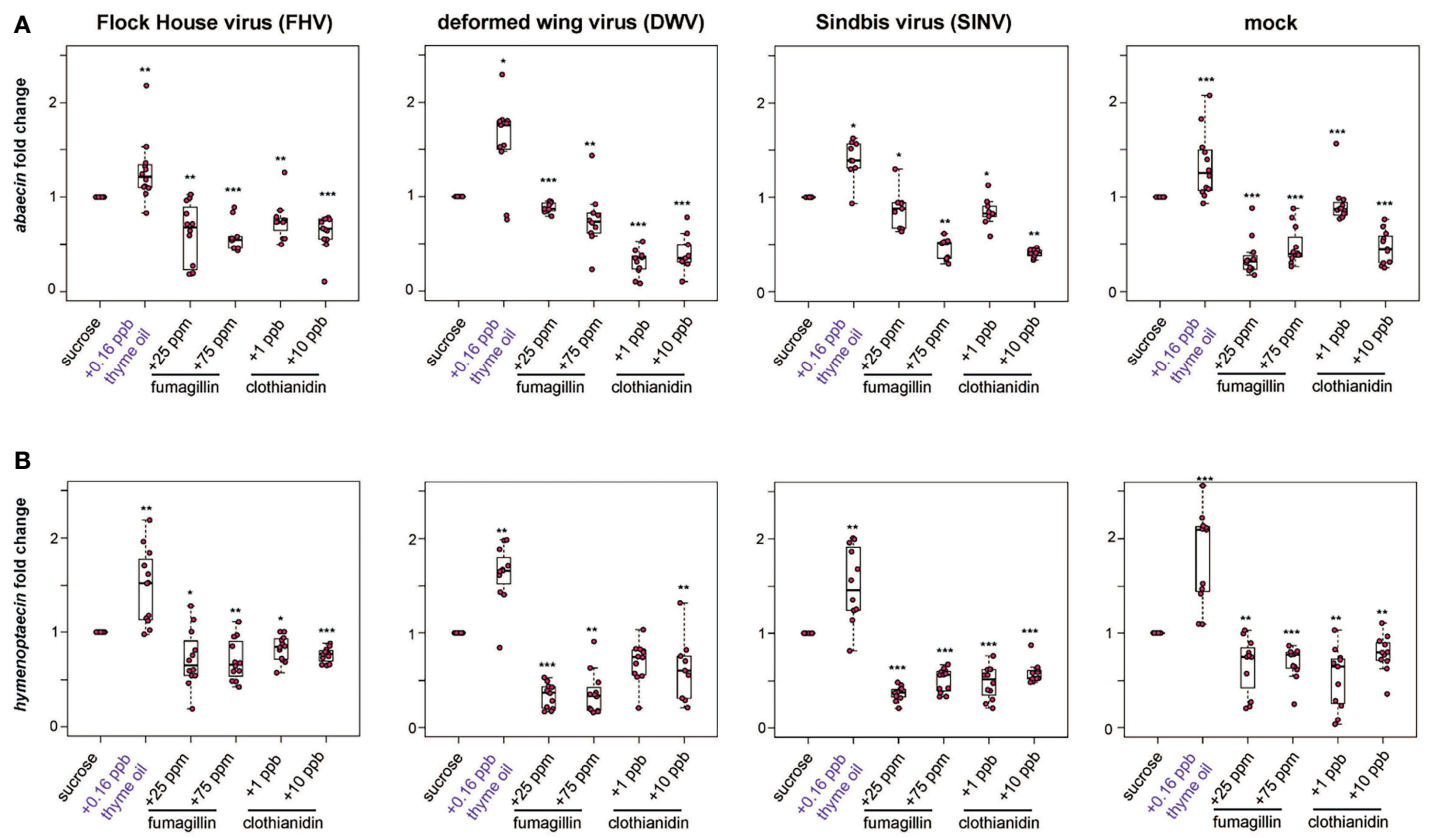

FIGURE 5 | Expression of antimicrobial peptides encoding genes was greater in bees fed thyme oil augmented sucrose syrup and lower in bees fed fumagillin or clothianidin containing sucrose syrup. The expression of two antimicrobial peptides (abaecin and hymenoptaecin) was assessed in mock and virus-infected bees fed sucrose syrup containing additives. (A) In virus- and mock-infected bees (i.e., FHV, DWV, SINV), abaecin expression was higher in bees fed sucrose syrup containing thyme oil and lower in bees fed sucrose syrup containing fumagillin (25 ppm or $75 \mathrm{ppm}$ ) or clothianidin (1 ppb or $10 \mathrm{ppb}$ ) compared to bees fed sucrose only. (B) In virus-infected bees (i.e., FHV, DWV, SINV), hymenoptaecin expression was higher in bees fed sucrose syrup containing thyme oil and lower in bees fed sucrose syrup containing fumagillin (25 ppm or $75 \mathrm{ppm}$ ) or clothianidin (1 ppb or $10 \mathrm{ppb).} \mathrm{Hymenoptaecin} \mathrm{expression} \mathrm{was} \mathrm{higher} \mathrm{in} \mathrm{mock-infected} \mathrm{bees} \mathrm{fed} \mathrm{sucrose} \mathrm{syrup}$ augmented with $0.16 \mathrm{ppb}$ thyme oil, but lower in mock-infected bees fed either fumagillin (i.e., $25 \mathrm{ppm}$ or $75 \mathrm{ppm}$ ) or clothianidin (1 ppb or $10 \mathrm{ppb)} \mathrm{containing}$ sucrose syrup. Data were analyzed by a pairwise Wilcoxon Rank Sums with a Benjamini-Hochberg correction for multiple comparisons. Asterisks indicate a significant change in gene expression compared to sucrose only control; significance levels: ${ }^{*} p<0.05 ;{ }^{* \star} p<0.005 ;{ }^{* \star \star} p<0.0005$. This figure shows representative biological replicate for the expression of each gene (i.e., rep1 for abaecin and rep3 for hymenoptaecin). The data for one additional biological replicate is presented in Supplemental Figures S7, S8. Raw data are included in Supplemental Tables S17-S20.

FHV-infection coupled with fumagillin or clothianidin containing sucrose syrup resulted in lower levels of hymenoptaecin expression compared to levels in bees fed plain sucrose syrup (i.e., $25 \mathrm{ppm}$ fumagillin, 0.72 fold, $p=0.019 ; 75$ ppm fumagillin, 0.7 fold, $p=0.002 ; 1 \mathrm{ppb}$ clothianidin, 0.83 fold, $p=0.027$; and $10 \mathrm{ppb}$ clothianidin, 0.76 fold, $p<0.001$ ) (Figure 5B). Likewise, DWV-infected honey bees fed thyme oil augmented sucrose syrup had 1.62 fold higher hymenoptaecin expression relative to bees fed sucrose syrup only $(p=0.002)$. However, hymenoptaecin expression was lower in DWV-infected bees fed sucrose syrup containing $25 \mathrm{ppm}$ fumagillin ( 0.34 fold, $p<0.001), 75$ ppm fumagillin (0.36 fold, $p<0.001), 1 \mathrm{ppb}$ clothianidin ( 0.69 fold, $p=0.001)$, and 10 ppb clothianidin $(0.62$ fold, $p=0.006$ ) than levels in bees fed only sucrose syrup (Figure 5B). SINV-infected bees fed sucrose syrup supplemented with $0.16 \mathrm{ppb}$ thyme oil exhibited 1.51 fold greater expression of hymenoptaecin, relative to bees fed sucrose syrup only $(p=0.001)$. Bees infected with SINV and fed fumagillin or clothianidin containing sucrose syrup had lower levels of hymenoptaecin expression compared to bees fed sucrose syrup alone (i.e., $25 \mathrm{ppm}$ fumagillin, 0.37 fold; $75 \mathrm{ppm}$ fumagillin, 0.51 fold; $1 \mathrm{ppb}$ clothianidin, 0.48 fold; and $10 \mathrm{ppb}$ clothianidin, 0.58 fold; all with $p<0.001$ ) (Figure 5B). Similar trends in hymneoptaecin expression were observed in mockinfected bees fed thyme oil, which exhibited 1.8 fold greater expression relative to bees fed sucrose syrup $(p<0.001)$, whereas mock-infected bees exposed to chemical stressors had reduced hymenoptaecin expression levels (i.e., in $25 \mathrm{ppm}$ fumagillin, 0.66 fold, $p=0.004 ; 75 \mathrm{ppm}$ fumagillin, 0.68 fold, $p<0.001 ; 1 \mathrm{ppb}$ clothianidin, 0.52 fold, $p=0.004$; and $10 \mathrm{ppb}$ clothianidin, 0.78 fold, $p=0.004$ ) (Figure 5B). Similar trends in hymenoptaecin expression were observed in one additional biological replicate of this experiment except in rep1, hymenoptaecin expression in bees fed thyme oil and either infected with FHV or SINV exhibited similar levels of expression to bees fed only sucrose syrup (Supplemental Figure S8).

\subsubsection{Greater Vitellogenin Expression in Thyme Oil Fed Bees, Reduced in Fumagillin and Clothianidin Fed Bees}

In honey bees, vitellogenin $(v g)$ has numerous functions including roles in immunity and stress resistance [reviewed in (77)]. Overall, the trends in $v g$ expression were similar to the trends observed for 
other honey bee immune genes including dcr-like, ago2, abaecin, and hymeptaecin. Virus infection in conjugation with thyme oil augmented diets resulted in higher levels of $v g$ expression compared to virus-infected bees fed sucrose only (i.e., FHV1.47 fold, $p=0.023$; DWV- 1.42 fold, $p<0.001$; SINV- 1.23 fold, $p=0.01$ ). The expression of $v g$ was highest for $0.16 \mathrm{ppb}$ thyme oil fed, mock-infected bees, which exhibited 2.71 fold greater expression than bees fed sucrose only $(p=0.0001)$. Whereas virus-infected bees fed either fumagillin or clothianidin containing diets had lower expression of $v g$. Specifically, in FHVinfected bees fed chemical containing sucrose syrup resulted in reduced $v g$ expression (i.e., $25 \mathrm{ppm}$ fumagillin, 0.86 fold, $p=0.023$; 75 ppm fumagillin, 0.62 fold, $p=0.002 ; 1 \mathrm{ppb}$ clothianidin, 0.77 fold, $p<0.001$; and $10 \mathrm{ppb}$ clothianidin, 0.74 fold, $p=0.002$ ) compared to bees fed sucrose syrup (Figure 6). Analogously, dual stressed bees resulted in reduced $v g$ expression in DWV-infected bees fed sucrose syrup containing $25 \mathrm{ppm}$ fumagillin ( 0.84 fold, $p$ $=0.013), 75 \mathrm{ppm}$ fumagillin (0.42 fold, $p<0.001), 1 \mathrm{ppb}$ clothianidin ( 0.8 fold, $p=0.001)$, and $10 \mathrm{ppb}$ clothianidin $(0.68$ fold, $p<0.001$ ) compared to bees fed sucrose syrup (Figure 6). Vitellogenin expression was reduced in SINV-infected bees fed with sucrose syrup containing 25 ppm fumagillin ( 0.51 fold, $p<$ $0.001), 75$ ppm fumagillin ( 0.34 fold, $p<0.001), 1 \mathrm{ppb}$ clothianidin ( 0.73 fold, $p<0.0001)$, and $10 \mathrm{ppb}$ clothianidin ( 0.77 fold, $p=$ 0.002) compared to bees fed sucrose syrup (Figure 6). In general, similar trends in $v g$ expression were observed in mock-infected bees exposed to a single stressor, i.e., in bees fed sucrose syrup containing $25 \mathrm{ppm}$ fumagillin ( 0.81 fold, $p=0.001), 75 \mathrm{ppm}$ fumagillin ( 0.85 fold, $p=0.001$ ), $1 \mathrm{ppb}$ clothianidin ( 0.83 fold, $p<$ 0.001 ), and $10 \mathrm{ppb}$ clothianidin ( 0.82 fold, $p=0.001$ ) compared to bees fed sucrose syrup (Figure 6). The expression of $v g$ as analyzed in one additional biological replicate followed similar trends except in rep1, FHV-infected bees fed $10 \mathrm{ppb}$ clothianidin and SINV-infected bees fed 25 ppm fumagillin, vitellogenin expression was constant relative to bees fed sucrose syrup (Supplemental Figure S9).

\section{DISCUSSION}

Honey bee health is impacted by numerous factors including pathogens and chemical stressors. These stressors impact honey bee health at the colony, individual bee, and cellular levels. Honey bees have evolved various strategies to mitigate these threats (97, 177-179). However, the impact of multiple, simultaneous biotic and abiotic stressors on honey bee health and longevity is currently not well understood, and difficult to assess at the colony level due to the large number of confounding variables (e.g., weather, colony management, pathogen exposure, co-infections). Therefore, we performed laboratory-based experiments to examine the impact of virus infection in the context of putative chemical stimulant (i.e., thyme oil) and stressors (i.e., fumagillin and clothianidin), while limiting the effects of additional compounding variables. The results described herein demonstrate that honey bees fed sucrose syrup supplemented with 0.16 ppb thyme oil harbored $25-87 \%$ less virus than bees fed only sucrose syrup. This trend was consistent for a panel of viruses including FHV, SINV-GFP, and DWV. Honey bees fed thyme oil exhibited greater expression of genes involved in antiviral defense including the RNAi pathway (i.e., ago2 and dcr-like) and antimicrobial peptide genes regulated by Toll and Imd pathways (i.e., abaecin and hymenoptaecin), as well as a gene involved in immune competence and a marker of the overall bee health, vitellogenin. Together these results indicate that thyme oil stimulates honey bee immune responses and mitigates virus infections.

This is in line with previous studies that have documented modulation of honey bee gene expression in response to phytochemicals. Specifically, in the context of natural DWV infections, Palmer-Young et al. demonstrated greater hymenoptaecin expression (12.9 to 61-fold) in honey bees fed 0.16 ppb thymol relative to controls (104). Likewise, Mao et al. demonstrated that honey bees fed p-coumaric acid, a common pollen phytochemical, had greater expression of two other
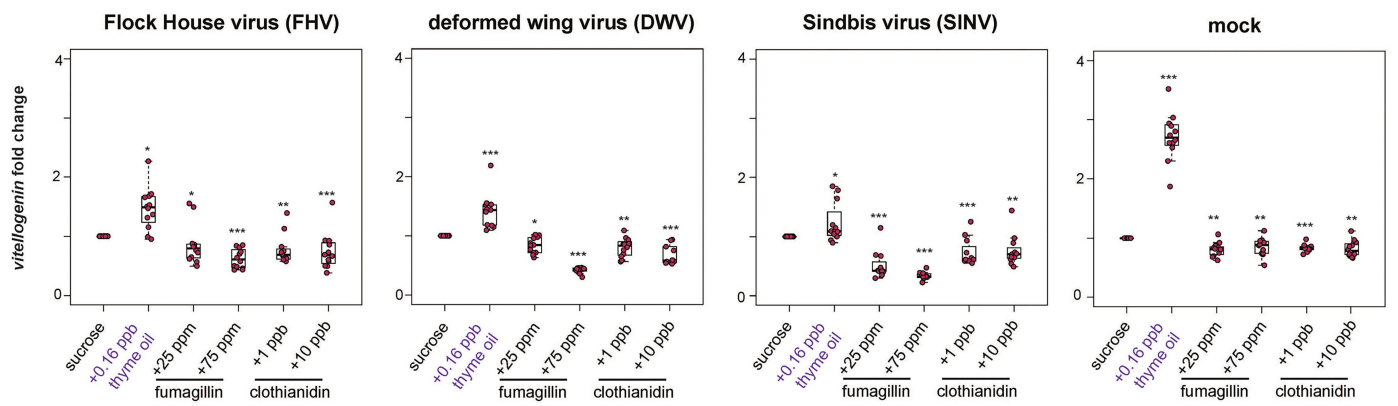

FIGURE 6 | Vitellogenin expression was higher in bees fed sucrose syrup containing thyme oil and lower in bees fed sucrose syrup containing fumagillin or clothianidin. Vitellogenin expression was assessed using qPCR and the relative gene expression was analyzed using the $\Delta \Delta \mathrm{Ct}$ method with normalization to rp/8 and relative to expression in mock or virus-infected bees fed sucrose syrup only. In virus-infected (i.e., FHV, DWV, SINV) and mock-infected honey bees vitellogenin expression was greater in bees fed sucrose syrup containing thyme oil and reduced in bees fed sucrose syrup containing fumagillin (25 ppm or 75 ppm) or clothianidin (1 ppb or 10 ppb) relative to sucrose only fed bees. Asterisks indicate a significant change in gene expression compared to sucrose only control; significance levels: ${ }^{*} p<0.05 ;{ }^{* \star} p<0.005 ;{ }^{* \star} p<0.0005$. This figure shows representative biological replicate for vitellogenin expression. The data for one additional biological replicate is presented in Supplemental Figure S9. Raw data are included in Supplemental Tables S21, S22. 
antimicrobial peptide encoding genes (i.e., 1.2 fold defensin and 1.9 fold abaecin), as well as genes involved in detoxification (107). Our results, coupled with previous studies are promising and may indicate that thyme oil augmented diets, either naturally acquired or fed could be used to enhance individual bee immunocompetence and, in turn, mitigate virus-associated colony deaths. However, further investigation is required to determine the range of thymol concentrations that positively impact honey bee health, since exposure to higher doses of thymol (i.e., $16 \mathrm{ppm}$ ) were lethal in previous studies (104). Additional studies are also required to further investigate the precise mechanisms of action, while results to date suggest thymol stimulates the expression of key honey bee immune genes. The signal transduction cascades, sensors, transcription factors, and effector proteins involved have yet to be fully elucidated.

The impact of agrochemicals, including neonicotinoid insecticides on honey bee health and colony longevity is an important area of research that includes a large body of literature including numerous studies that have examined field relevant exposure, colony longevity, and the impacts on individual bees in laboratory-based experiments $(139,180-182)$. While acute toxicity is easy to measure in laboratory-based studies, sublethal impacts are more difficult to assess. Furthermore, the impact of sublethal doses of chemicals, including clothianidin, on the immune response and in turn the outcome of virus infection is even more difficult to discern. Previous studies demonstrated a negative impact of clothianidin (10 ppb) on the activation of Toll (NF- $\mathrm{KB} /$ Dorsal) pathway in honey bee larvae $(154,183)$. Clothianidin exposure enhances the transcription of the NF- $\mathrm{KB}$ inhibitor and suppresses the immune response. This eventually results in higher DWV replication (154). Similar to previous results, we determined that honey bees fed sucrose containing clothianidin (1 ppb) had reduced expression of key immune genes (i.e., ago2, dcr-like, abaecin, hymenoptaecin, and vitellogenin), which resulted in more severe virus infections, using virus abundance as a proxy for infection severity for a panel of viruses. Together our results coupled with those from previous studies, suggest that sublethal doses of clothianidin may increase the overall virus burden in a colony. However, honey bees fed sucrose syrup containing $10 \mathrm{ppb}$ clothianidin had virus levels that were similar to, or lower than, levels in bees fed only sucrose syrup. Although additional studies are needed, we hypothesize that bees fed $10 \mathrm{ppb}$ clothianidin may have been less suitable hosts for viruses, which are obligate intracellular pathogens and, thus, rely on healthy host cells for replication. An alternative hypothesis, which is not well supported by the data described herein is that reduced virus abundance in $10 \mathrm{ppb}$ clothianidin fed bees is due to hormesis (i.e., a dose-dependent beneficial biological response to a chemical stressor) $(184,185)$. Insecticide-induced hormesis has been reported to have 'positive' effects on survival, reproduction, and immunity in bees and other insects and is involved in various life stages and different insecticide active ingredients (184-187). The possibility of virus reduction due to hormetic effects was mentioned in another study that found DWV-infected honey bees fed 0.12 $0.35 \mathrm{ng}$ clothianidin per bee ( 1.2 - 3.5 ppb) had lower DWV levels than bees fed $0.05 \mathrm{ng}$ clothianidin per bee $(\sim 0.5 \mathrm{ppb})$ (143). However, in our study, the beneficial virus limiting response in bees fed $10 \mathrm{ppb}$ clothianidin did not correspond with greater immune gene expression, therefore the hormetic effect hypothesis is not well-supported.

Beekeepers use in-hive chemical treatments as part of integrated pest management (IPM) strategies to maintain health honey bee colonies. These beekeeper-applied treatments include miticides and the antifungal compound fumagillin, which is used to mitigate Nosema spp. infections. Previous studies indicated that fumagillin treatments may negatively impact bee health, therefore a limit of two treatments per colony is included as a label advisory. To further investigate the impacts of fumagillin treatment on the honey bee immune system and the outcome of virus infection, honey bees were fed sucrose containing the recommended dose of $25 \mathrm{ppm}$, or a greater dose of $75 \mathrm{ppm}$. We determined that virus abundance was higher in bees fed sucrose syrup containing $25 \mathrm{ppm}$ or $75 \mathrm{ppm}$ fumagillin, relative to bees fed sucrose syrup only. The greater virus abundance is likely due to immune suppression, as the expression of select honey bee immune genes (i.e., ago2, dcr-like, abaecin, hymenoptaecin, and vitellogenin) were reduced in fumagillin fed bees. Although future studies are warranted before adjusting recommendations for honey bee colony management, our results suggest that beekeepers should consider trade-off of reducing Nosema infections, but increasing virus abundance. This consideration may be more important at the end of the beekeeping season in temperate climates (i.e., late autumn), since DWV infections are usually greater at that time of year $(15,27,28)$. While the focus of our experiments was to evaluate the impact of dual stressors on individual honey bee health, we determined that honey bees exposed to a single stressor, i.e., fumagillin ( $25 \mathrm{ppm}$ or $75 \mathrm{ppm}$ ) or clothianidin (1 ppb) had reduced levels of key immune genes (i.e., ago2, dcr-like, abaecin, hymenoptaecin, and vitellogenin) compared to bees fed sucrose syrup alone. The reduced expression of vitellogenin in fumagillin or clothianidin (1 ppb) fed bees indicates poor health status of the host while the reduced expression of key immune genes suggests hindered immune responses.

Collectively, the results described herein indicate that 0.16 ppb thyme oil acts as an immunostimulant in honey bees and results in reduced levels of virus infection. Additional studies that further examine the kinetics of immune stimulation and the impact of multiple treatments on virus infections over a longer time frame are required to help move these studies beyond the laboratory and towards colony level investigations that may benefit beekeeping operations. It will also be important to examine the impact of simultaneous exposure to putative immune system stimulants including thyme oil, in the context of varying doses of chemical stressors (fungicide and/or insecticide) on the outcome of honey bee virus infections. In addition, chemical adjuvants can negatively impact the outcome of virus infections in the context of other chemical stressors, and therefore their impact also requires further investigation (188). Studies that more clearly mimic the real-world multifactorial and variable biotic and abiotic stressors encountered by honey bees, and other beneficial insect pollinators, will be instrumental to the 
development of strategies aimed at mitigating their losses $(11,79$, 133, 189-192).

\section{MATERIALS AND METHODS}

\subsection{Honey Bees}

Honey bee colonies were originally established as packages containing naturally mated Apis mellifera carnica queens and maintained in Langstroth hives in an apiary located at Montana State University's Horticulture Farm in Bozeman, MT, USA. Frames of capped brood with emerging bees were obtained from established colonies one day prior to each experiment and kept at $32^{\circ} \mathrm{C}$ and in a laboratory incubator overnight. Age-matched $(\sim 24$ $\mathrm{h}$ post-emergence) adult female, worker bees were collected and housed in modified deli-containers and randomly assigned into treatment groups. Honey bees in each treatment group were maintained in laboratory incubators at $32^{\circ} \mathrm{C}$ and $\sim 20 \%$ relative humidity and fed $50 \%$ sucrose solution ad libitum with or without additives including thyme oil, fumagillin, and clothianidin as described below. Experiments described herein were carried out using honey bees collected from three separate colonies obtained during May-August 2020, designated as rep1, rep2, and rep3.

\subsection{Virus Preparation}

\subsubsection{Flock House Virus}

Flock House virus (FHV) was propagated in Drosophila melanogaster Schneider 2 (S2) cells derived from $D$. melanogaster embryos. S2 cells were grown as monolayers in Schneider's Drosophila medium supplemented with $10 \%$ heatinactivated fetal bovine serum (Life Technologies) and 1\% penicillin-streptomycin as per manufacturer's instructions. To generate FHV particles, $4 \times 10^{7} \mathrm{~S} 2$ cells $/ \mathrm{ml}$ were seeded in a sterile T75 flask (Thermo Scientific). An aliquot of FHV was kindly provided by Dr. Anette Schneemann (The Scripps Research Institute, La Jolla, California). S2 cells were infected with FHV at a multiplicity of infection of $1 \mathrm{pfu} / \mathrm{cell}$ and incubated at $28^{\circ} \mathrm{C}$ for $48 \mathrm{~h}$ as previously described (193). After incubation, the cells were lysed by addition of $10 \%$ ( $\mathrm{vol} / \mathrm{vol}$ ) Nonidet P-40 and incubated on ice for $10 \mathrm{~min}$ with periodic swirling. Cell debris was pelleted in a Sorvall LYNX 4000 Centrifuge (Thermo Fisher) at $13,800 \mathrm{x} g$ for $10 \mathrm{~min}$ at $4^{\circ} \mathrm{C}$ and the clarified supernatant was transferred to a fresh tube. Virus was pelleted through a $1 \mathrm{~mL}$ volume of $30 \%$ (wt/wt) sucrose in 50 mM HEPES (pH 7) at 40,000 rpm for $2.5 \mathrm{~h}$ at $11^{\circ} \mathrm{C}$ in a SW41 Ti Swinging-Bucket Rotor (Beckman Coulter). The pellets were resuspended in $0.5 \mathrm{~mL} 50 \mathrm{mM}$ HEPES ( $\mathrm{pH} \mathrm{7)}$ and centrifuged at 10,000 rpm for $10 \mathrm{~min}$ to remove any insoluble material. The clarified supernatant was layered on continuous sucrose gradients $(40 \%, 35 \%, 30 \%, 25 \%, 20 \%, 15 \%$ and $10 \%$ (wt/wt)) and centrifuged at $40,000 \mathrm{rpm}$ for $1.5 \mathrm{~h}$ at $11^{\circ} \mathrm{C}$ to sediment the virus halfway down the tube. The sedimented virus was further pelleted in $10 \mathrm{mM}$ Tris $\mathrm{HCl}$ buffer ( $\mathrm{pH} 7.5$ ) at 40,000 rpm for 2.5 $\mathrm{h}$ at $11^{\circ} \mathrm{C}$ for injections in honey bees. RNA was isolated from
$100 \mu \mathrm{L}$ virus preparations (as described below) and FHV abundance was quantified by RT-PCR and copy number was based on a standard curve. The dose utilized for laboratory-based honey bee infection studies was $3.5 \times 10^{8}$ FHV RNA copies per bee. FHV RNA 2 plasmid standards were used as templates, with concentrations ranging from $10^{3}$ to $10^{9}$ copies per reaction to create a linear standard curve, with a limit of detection of $10^{3}$ copies of FHV cDNA using primers FHV-FW and FHV-REV (Supplemental Table S1). The linear equation for the plasmid standard for FHV was $\mathrm{Ct}=-3.240 \mathrm{x}+40.138\left(\mathrm{R}^{2}=0.980\right.$, efficiency $=103 \%$ ) where ' $\mathrm{x}$ ' is the $\log$ (FHV RNA copies).

\subsubsection{Deformed Wing Virus}

DWV was propagated in white eyed pupae collected from a frame of capped brood. Specifically, honey bee pupae were injected with $3.41 \times 10^{7}$ DWV RNA copies in $2 \mu \mathrm{L}$ between the $2^{\text {nd }}$ and $3^{\text {rd }}$ integuments of the abdomen using microcapillary glass needle and a Harbo syringe (Honey bee Insemination Service). Post-injection, pupae were held at $30^{\circ} \mathrm{C}$ in a humid incubator for the course of infection. Infection progression was tracked by the eye color to ensure the pupae were alive. Live pupae were harvested at 10 days post infection and place in a 2 $\mathrm{mL}$ safe-lock Eppendorf tube with $1 \mathrm{~mL}$ PBS ( $\mathrm{pH} 7.4$ ) and homogenized using a Tissue Lyser II (Qiagen) at $30 \mathrm{~Hz}$ for $2 \mathrm{~min}$. The homogenate was centrifuged at $14,000 \mathrm{x} g$ for $15 \mathrm{~min}$ at $4^{\circ} \mathrm{C}$ and the clarified supernatant was transferred to a fresh tube. DWV RNA copies were quantified using qPCR to be $3.41 \times 10^{7}$ DWV RNA copies/ $\mu \mathrm{L}$. The inoculum was tested for copurifying/ contaminating viruses (ABPV, BQCV, CBPV, IAPV, KBV, LSVs, and SBV) via PCR. No other viruses except DWV were detected via PCR. (Supplemental Figure S11). The dose utilized for laboratory-based honey bee infection studies was $3.5 \times 10^{8}$ DWV RNA copies per bee. DWV plasmid standards were used as templates, with concentrations ranging from $10^{3}$ to $10^{9}$ copies per reaction to create a linear standard curve, with a limit of detection of $10^{3}$ copies of DWV cDNA using primers DWV-F 1170 and DWV-R 1364 (Supplemental Table S1). The linear equation for the plasmid standard for DWV was $\mathrm{Ct}=-3.469 \mathrm{x}+$ $40.803\left(R^{2}=0.999\right.$, efficiency $\left.=94.5 \%\right)$ where ' $x$ ' is the $\log (\mathrm{DWV}$ RNA copies).

\subsubsection{Sindbis-Green Fluorescent Protein Tagged}

We utilized a recombinant model virus, Sindbis virus expressing green fluorescent protein $(42,93,194)$. We and others have used SINV to investigate honey bee, fruit fly, and mosquito antiviral defense mechanisms $(42,43,61,93)$. SINV was propagated in Baby Hamster Kidney fibroblast (BHK-21) cells. BHK-21 cells were grown as a monolayer in Eagle's Minimum Essential Medium with $10 \%$ fetal bovine serum. A $90 \%$ confluent flask was infected with a multiplicity of infection of 0.001 as previously described (94). Infected cells were incubated at $37^{\circ} \mathrm{C}$ with $5 \%$ carbon dioxide for $24 \mathrm{~h}$. Cells were collected, and the cell debris was removed by centrifugation at $1000 \mathrm{x} g$ for $10 \mathrm{~min}$. The clarified supernatant was quantified using a standard plaque assay (93). Each bee was injected with 3,750 plaque forming units (PFUs) SINV. SINV-GFP plasmid standards were used as 
templates, with concentrations ranging from $10^{3}$ to $10^{9}$ copies per reaction to create a linear standard curve, with a limit of detection of $10^{3}$ copies of SINV-GFP cDNA using primers qSindbisFW4495 and qSindbisREV4635 (Supplemental Table S1). The linear equation for the plasmid standard for SINV-GFP was $C t=-3.335 x+40.137\left(R^{2}=0.993\right.$, efficiency $\left.=99.5 \%\right)$ where ' $\mathrm{x}$ ' is the $\log$ (SINV-GFP RNA copies).

\subsection{Honey Bee Virus Infection}

Age-matched ( $24 \mathrm{~h}$ post-emergence) adult female, worker bees were cold anesthetized at $4^{\circ} \mathrm{C}$ for $10 \mathrm{~min}$ prior to intrathoracic injection of virus or buffer (mock-infection). Intra-thoracic injections were performed using a Harbo syringe (Honey Bee Insemination Service) and microcapillary glass needles, made by pulling borosilicate glass capillary tubes (100 mm long, $1 \mathrm{~mL}$ capacity, Kimble-Chase) with a coil temperature of $61^{\circ} \mathrm{C}$ on the PC-10 Dual-Stage Glass Micropipette Puller (Narishige). Honey bees were infected with $3.5 \times 10^{8}$ FHV RNA copies/bee in $10 \mathrm{mM}$ Tris $\mathrm{HCl}$ buffer $\mathrm{pH} 7.5,3.5 \times 10^{8} \mathrm{DWV}$ RNA copies/bee in $10 \mathrm{mM}$ Tris HCl buffer pH 7.5 or 3,750 PFUs SINV-GFP. Mockinfected bees were injected with $2 \mu \mathrm{L}$ buffer $(10 \mathrm{mM}$ Tris $\mathrm{HCl}$, $\mathrm{pH}$ 7.5).

\subsection{Honey Bee Diet Preparation}

Post-injection, honey bees were housed in modified deli containers for the duration of the study. Bees in the control group were fed $50 \%$ sucrose syrup only, whereas bees in treatment groups were fed sucrose syrup containing one of the following additives: 0.16 ppb thyme oil (Body wonders), Fumagilin- ${ }^{\circledR}{ }^{\circledR}$, fumagillin dicyclohexyl ammonium (Medivet Pharmaceuticals Ltd.) at manufacturer's recommended dose of $25 \mathrm{ppm}$ or a higher dose of $75 \mathrm{ppm}$, or clothianidin at the field relevant sublethal concentration of $1 \mathrm{ppb}$ or near lethal dose of $10 \mathrm{ppb}(130,195$, 196). Thyme oil contains $10 \%$ - 64\% thymol ( $37 \%$ average) depending on the plant species, geographical sources, and harvest season, which may affect the volatile composition of the plant (113, $116-118)$. We estimate that $0.16 \mathrm{ppb}$ thyme oil used in this experiment may contain approximately $0.06 \mathrm{ppb}$ (60 ppb) thymol (37\% thymol in $0.16 \mathrm{ppb}$ thyme oil corresponds to $\sim 60$ $\mathrm{ppb}$ ). For clothianidin treatments we utilized the commercially available Poncho ${ }^{\circledR} 600$, which contains $48 \%$ of the active ingredient clothianidin. A working stock of $1000 \mathrm{ppb}$ clothianidin was prepared by 1:10 serial dilutions in 50\% sucrose solution, which was further diluted in 50\% sucrose to prepare $1 \mathrm{ppb}$ (i.e., $10 \mathrm{ul}$ of $1000 \mathrm{ppb}$ Poncho ${ }^{\circledR}$ 600) and $10 \mathrm{ppb}$ (i.e., 100 ul of $1000 \mathrm{ppb}$ Poncho ${ }^{\circledR}$ 600) clothianidin solutions. Honey bees were fed sucrose solution either alone or with additives using cage feeders that were made by putting two holes on each side of a $1.5 \mathrm{~mL}$ centrifuge tube; sucrose solution was checked daily and refilled as needed throughout the study.

\subsection{RNA Isolation}

Individual honey bee sample was dissected into head, thorax, and abdomen. The abdomen was utilized for further analysis since it is distal to the injection site and thus virus infection naturally spread into that tissue, and it contains the immune cell generating fat body. Honey bee abdomens were transferred into $2 \mathrm{~mL}$ Eppendorf safe-lock tubes and homogenized in 300 $\mu \mathrm{L}$ deionized water with a sterile steel ball $(5 \mathrm{~mm})$ using a Tissue Lyser II (Qiagen) at $30 \mathrm{~Hz}$ for $2 \mathrm{~min}$. An equal volume $(300 \mu \mathrm{L})$ of TRIzol reagent (Invitrogen) was added to homogenate and then samples were vortexed for $15 \mathrm{~s}$ followed by a $5 \mathrm{~min}$ incubation at room temperature. Next, $100 \mu \mathrm{L}$ chloroform was added and each sample was shaken by hand for $15 \mathrm{~s}$ and incubated at room temperature for $2 \mathrm{~min}$. Samples were then centrifuged at $12,000 \mathrm{x} g$ at $4^{\circ} \mathrm{C}$ for $15 \mathrm{~min}$ and the aqueous phase was transferred to a fresh $1.5 \mathrm{~mL}$ centrifuge tube. An equal volume of isopropanol was added to the aqueous phase, vortexed, and incubated at room temperature for $10 \mathrm{~min}$ to precipitate the nucleic acid. The nucleic acid was pelleted by centrifugation at $12000 \mathrm{x} g$ at $4^{\circ} \mathrm{C}$ for $10 \mathrm{~min}$. Supernatant was carefully removed and the pellets were washed with $75 \%$ ethanol by centrifugation at $7500 \mathrm{x} g$ at $4^{\circ} \mathrm{C}$ for $5 \mathrm{~min}$. The resulting supernatant was discarded, and the pellets were air dried for $10 \mathrm{~min}$ at room temperature, then dissolved in $50 \mu \mathrm{L}$ deionized water. RNA concentrations were assessed on Nanodrop 2000 spectrophotometer (Thermo Fisher). All RNA samples were stored in $-80^{\circ} \mathrm{C}$ until further analysis.

\subsection{Reverse Transcription/cDNA Synthesis}

Reverse transcription reactions were carried out to synthesize complimentary DNA (cDNA) by incubating 2,000 ng of RNA with M-MLV reverse transcriptase (Promega) and $500 \mathrm{ng}$ random hexamer primers (IDT) for $1 \mathrm{~h}$ at $37^{\circ} \mathrm{C}$ according to manufacturer's instructions. The resulting cDNA was diluted 1:2 with sterile distilled water.

\subsection{Polymerase Chain Reaction}

Polymerase chain reaction (PCR) was used to test mock-infected bees in all experimental replicates for pre-existing infections with honey bee infecting viruses, since bees were obtained from honey bee colonies that may have varying levels of naturally prevalent bee infecting viruses (i.e., BQCV, CBPV, ABPV, DWV, IAPV, $\mathrm{KBV}, \mathrm{SBV}$, LSVs 1-4). To reduce the number of individual PCR tests, individual bee cDNA samples $(n=11-12)$ were pooled, resulting in three pooled samples per treatment. Each pool was tested for pre-existing virus infections using pathogen-specific primers (Supplemental Table S1 and Supplemental Figure S10). PCR was performed according to standard methods (197). In brief, $2 \mu \mathrm{L}$ cDNA template was combined with 10 pmol of each forward and reverse primer, and amplified with Denville ChoiceTaq polymerase (Thomas Scientific) according to the manufacturer's instructions using the following cycling conditions: $95^{\circ} \mathrm{C}$ for $5 \mathrm{~min}, 95^{\circ} \mathrm{C}$ for $30 \mathrm{~s}, 57^{\circ} \mathrm{C}$ for $30 \mathrm{~s}, 72^{\circ} \mathrm{C}$ for $30 \mathrm{~s}, 35$ cycles, followed by final elongation at $72^{\circ} \mathrm{C}$ for $4 \mathrm{~min}$.

\subsection{Quantitative PCR}

Quantitative PCR was used to quantify relative abundances of viruses and honey immune gene transcripts using the primers listed in Supplemental Table S1. All qPCR reactions were performed in triplicate with $2 \mu \mathrm{L}$ of cDNA template. Each 20 $\mu \mathrm{L}$ reaction contained $1 \times$ ChoiceTaq Mastermix (Thomas 
Scientific), $0.4 \mu \mathrm{M}$ each forward and reverse primer, $1 \times$ SYBR Green (Life Technologies), and $3 \mathrm{mM} \mathrm{MgCl}_{2}$. A CFX Connect Real Time instrument (BioRad) was used to carry out reactions with the following thermo-profile: pre-incubation at $95^{\circ} \mathrm{C}$ for 1 min followed by 40 cycles of $95^{\circ} \mathrm{C}$ for $10 \mathrm{~s}, 60^{\circ} \mathrm{C}$ for $20 \mathrm{~s}$, and $72^{\circ} \mathrm{C}$ for $15 \mathrm{~s}$; final extension at $72^{\circ} \mathrm{C}$ for $1 \mathrm{~min}$, followed by melt curve analysis. Reactions without template were carried out as negative controls. The qPCR specificity was verified through melt point analysis and gel electrophoresis of select samples. The sequence amplicons were previously verified by chaintermination sequencing. As described above in section 4.2 for virus stock quantification, virus abundance in individual bee samples was determined relative to a standard curve that was generated by the use of virus amplicon specific plasmids, with concentrations ranging from $10^{3}$ to $10^{9}$ copies per reaction, as templates to create linear standard curves. The linear equations for each virus amplicon are included in section 4.2 above. The qPCR and mortality data for individual samples is included in Supplemental Tables S3, S5. The virus fold change for dead and live virus-infected honey bees fed chemical treatments was plotted for each treatment group and no significant difference in fold change was recorded in dead vs. live bees. Thus, in our analyses, data from dead and live bees was combined and presented.

To assess the relative expression of honey bee genes including immune genes (i.e., argonaute-2, dicer-like, abaecin, hymenoptaecin, heat shock protein 90, heat shock protein 70 cognate 4, protein lethal (2) essential for life-like), and vitellogenin, relative to the expression of a reference gene (i.e., ribosomal protein L8) was carried out using the gene-specific primer sets in Supplemental Table S1 and the $\Delta \Delta \mathrm{Ct}$ method (198). Specifically, the relative expression of host genes was determined by a ranked $\Delta \Delta \mathrm{Ct}$ method in which the $\Delta \mathrm{Ct}$ was calculated by subtracting the rpl8 $\mathrm{Ct}$ value from the $\mathrm{Ct}$ of the gene of interest. Then, the within-group $\Delta \mathrm{Ct}$ values were ranked from highest to lowest, and the relevant corresponding control $\Delta \mathrm{Ct}$ value was subtracted from the treatment group $\Delta \mathrm{Ct}$ to obtain the $\Delta \Delta \mathrm{Ct}$. The fold-change in cDNA abundance was calculated by the equation $2^{-\Delta \Delta C t}$. Efficiency of each primer set was evaluated using cDNA dilution series and calculated by plotting $\log _{10}$ of the concentration versus the crossing point threshold $(\mathrm{C}(\mathrm{t}))$ values and using the primer efficiency equation $\left.\left(10^{(1 / \text { Slope })-1}\right) \times 100\right)$. The efficiency equations of the primers utilized for honey bee immune genes are- ago-2 $\mathrm{Cp}=-3.36 \mathrm{x}+$ $30.28, \mathrm{R}^{2}=0.99 ;$ dcr-like $\mathrm{Cp}=-3.56 \mathrm{x}+31.22, \mathrm{R}^{2}=0.99 ;$ abaecin $\mathrm{Cp}=-3.37 \mathrm{x}+29.8, \mathrm{R}^{2}=0.99 ;$ hymenoptaecin $\mathrm{Cp}=-3.44 \mathrm{x}+$ $30.50, \mathrm{R}^{2}=0.99 ; h s p 90 \mathrm{Cp}=-3.43 \mathrm{x}+32.98, \mathrm{R}^{2}=0.99 ;$ hsc70-4 $\mathrm{Cp}=-3.36 \mathrm{x}+31.52, \mathrm{R}^{2}=0.99 ; p l 2 \mathrm{Cp}=-3.16 \mathrm{x}+30.12, \mathrm{R}^{2}=0.99$; vitellogenin $C p=-3.04 \mathrm{x}+29.44, \mathrm{R}^{2}=0.99$.

\subsection{Statistical Analysis}

All data were analyzed using $\mathrm{R}$ v4.0.2 in RStudio V1.3.1073. Pairwise comparisons for virus abundance and gene expression were evaluated using the pairwise.wilcox.test function in the base $\mathrm{R}$ stats package to perform a Wilcoxon Rank Sums test with Benjamini-Hochberg correlation for multiple comparisons (199).

\section{DATA AVAILABILITY STATEMENT}

The majority of the data generated or analyzed during this study are included in this published article and its Supplementary Material files (available online). Additional data are available from the corresponding author upon request.

\section{AUTHOR CONTRIBUTIONS}

Conceptualization, FP, KD, and MF. Methodology, FP, KD, and MF. Formal analysis, FP. Investigation, FP and MF. Resources, MF. Data curation, FP and MF. Writing-original draft preparation, FP and MF. Writing-review and editing, FP and MF. Visualization, FP and MF. Supervision, MF. Project administration, MF. Funding acquisition, MF. All authors have read and agreed to the published version of the manuscript.

\section{FUNDING}

The Flenniken laboratory is supported by the National Science Foundation CAREER Program (Award Number 1651561), Montana Department of Agriculture Specialty Crop Block Grant Program (Award Number 19SCG04703), and United States Department of Agriculture National and Food Research Initiative (USDA-NIFA) Hatch Multistate Funding (NC-1173). The funders had no role in study design, data collection and analysis, decision to publish, or preparation of this manuscript.

\section{ACKNOWLEDGMENTS}

We are grateful to Dr. Marie Pizzorno for help with producing the DWV stock and Emma Garcia for initial literature search and pilot studies. We would also like to thank the members of Flenniken laboratory (Alex McMenamin, Brian Ross, and Naomi Kaku) for reviewing this manuscript prior to publication.

\section{SUPPLEMENTARY MATERIAL}

The Supplementary Material for this article can be found online at: https://www.frontiersin.org/articles/10.3389/fimmu.2021. 747848/full\#supplementary-material 


\section{REFERENCES}

1. Gallai N, Salles J-M, Settele J, Vaissière BE. Economic Valuation of the Vulnerability of World Agriculture Confronted With Pollinator Decline. Ecol Economics (2009) 68(3):810-21. doi: 10.1016/j.ecolecon.2008.06.014

2. Eilers EJ, Kremen C, Smith Greenleaf S, Garber AK, Klein A-M. Contribution of Pollinator-Mediated Crops to Nutrients in the Human Food Supply. PloS One (2011) 6(6):e21363. doi: 10.1371/journal.pone. 0021363

3. Klein A-M, Vaissiere BE, Cane JH, Steffan-Dewenter I, Cunningham SA, Kremen C, et al. Importance of Pollinators in Changing Landscapes for World Crops. Proc R Soc B: Biol Sci (2007) 274(1608):303-13. doi: 10.1098/ rspb.2006.3721

4. Calderone NW. Insect Pollinated Crops, Insect Pollinators and US Agriculture: Trend Analysis of Aggregate Data for the Period 1992-2009. PloS One (2012) 7(5):e37235. doi: 10.1371/journal.pone.0037235

5. Kulhanek K, Steinhauer N, Rennich K, Caron DM, Sagili RR, Pettis JS, et al. A National Survey of Managed Honey Bee 2015-2016 Annual Colony Losses in the USA. J Apicult Res (2017) 56(4):328-40. doi: 10.1080/ 00218839.2017 .1344496

6. Spleen AM, Lengerich EJ, Rennich K, Caron D, Rose R, Pettis JS, et al. A National Survey of Managed Honey Bee 2011-12 Winter Colony Losses in the United States: Results From the Bee Informed Partnership. J Apicult Res (2013) 52(2):44-53. doi: 10.3896/IBRA.1.52.2.07

7. Steinhauer NA, Rennich K, Wilson ME, Caron DM, Lengerich EJ, Pettis JS, et al. A National Survey of Managed Honey Bee 2012-2013 Annual Colony Losses in the USA: Results From the Bee Informed Partnership. J Apicult Res (2014) 53(1):1-18. doi: 10.3896/IBRA.1.53.1.01

8. Traynor KS, Rennich K, Forsgren E, Rose R, Pettis J, Kunkel G, et al. Multiyear Survey Targeting Disease Incidence in US Honey Bees. Apidologie (2016) 47(3):325-47. doi: 10.1007/s13592-016-0431-0

9. vanEngelsdorp D, Caron D, Hayes J, Underwood R, Henson M, Rennich K, et al. A National Survey of Managed Honey Bee 2010-11 Winter Colony Losses in the USA: Results From the Bee Informed Partnership. J Apicult Res (2012) 51(1):115-24. doi: 10.3896/IBRA.1.51.1.14

10. Seitz N, Traynor KS, Steinhauer N, Rennich K, Wilson ME, Ellis JD, et al. A National Survey of Managed Honey Bee 2014-2015 Annual Colony Losses in the USA. J Apicult Res (2015) 54(4):292-304. doi: 10.1080/ 00218839.2016.1153294

11. McMenamin AJ, Brutscher LM, Glenny W, Flenniken ML. Abiotic and Biotic Factors Affecting the Replication and Pathogenicity of Bee Viruses. Curr Opin Insect Sci (2016) 16:14-21. doi: 10.1016/j.cois.2016.04.009

12. Brutscher LM, McMenamin AJ, Flenniken ML. The Buzz About Honey Bee Viruses. PloS Pathog (2016) 12(8):e1005757. doi: 10.1371/journal.ppat. 1005757

13. Cornman RS, Tarpy DR, Chen Y, Jeffreys L, Lopez D, Pettis JS, et al. Pathogen Webs in Collapsing Honey Bee Colonies. PloS One (2012) 7(8): e43562. doi: 10.1371/journal.pone.0043562

14. vanEngelsdorp D, Meixner MD. A Historical Review of Managed Honey Bee Populations in Europe and the United States and the Factors That May Affect Them. Invertebrate Pathol (2010) 103:S80-95. doi: 10.1016/j.jip.2009.06.011

15. Genersch E, von der Ohe W, Kaatz H, Schroeder A, Otten C, Büchler R, et al. The German Bee Monitoring Project: A Long Term Study to Understand Periodically High Winter Losses of Honey Bee Colonies*. Apidologie (2010) 41(3):332-52. doi: 10.1051/apido/2010014

16. Tentcheva D, Gauthier L, Zappulla N, Dainat B, Cousserans F, Colin ME, et al. Prevalence and Seasonal Variations of Six Bee Viruses in Apis Mellifera L. And Varroa Destructor Mite Populations in France. Appl Environ Microbiol (2004) 70(12):7185-91. doi: 10.1128/AEM.70.12.7185-7191.2004

17. Nazzi F, Le Conte Y. Ecology of Varroa Destructor, the Major Ectoparasite of the Western Honey Bee, Apis Mellifera. Annu Rev Entomol (2016) 61 (1):417-32. doi: 10.1146/annurev-ento-010715-023731

18. Boecking O, Genersch E. Varroosis - the Ongoing Crisis in Bee Keeping. I für Verbraucherschutz und Lebensmittelsicherheit (2008) 3(2):221-8. doi: 10.1007/s00003-008-0331-y

19. de D'Aubeterre JP, Myrold DD, Royce LA, Rossignol PA. A Scientific Note of an Application of Isotope Ratio Mass Spectrometry to Feeding by the Mite,
Varroa Jacobsoni Oudemans, on the Honeybee, Apis Mellifera L. Apidologie (1999) 30(4):351-2. https://hal.archives-ouvertes.fr/hal-00891594/document 20. Annoscia D, Brown SP, Di Prisco G, De Paoli E, Del Fabbro S, Frizzera D, et al. Haemolymph Removal by Varroa Mite Destabilizes the Dynamical Interaction Between Immune Effectors and Virus in Bees, as Predicted by Volterra's Model. Proc R Soc B: Biol Sci (2019) 286(1901):20190331. doi: 10.1098/rspb.2019.0331

21. Ramsey SD, Ochoa R, Bauchan G, Gulbronson C, Mowery JD, Cohen A, et al. Varroa Destructor Feeds Primarily on Honey Bee Fat Body Tissue and Not Hemolymph. Proc Natl Acad Sci (2019) 116(5):1792. doi: 10.1073/ pnas. 1818371116

22. Grozinger CM, Flenniken ML. Bee Viruses: Ecology, Pathogenicity, and Impacts. Annu Rev Entomol (2019) 64(1):205-26. doi: 10.1146/annurevento-011118-111942

23. Beaurepaire A, Piot N, Doublet V, Antunez K, Campbell E, Chantawannakul $\mathrm{P}$, et al. Diversity and Global Distribution of Viruses of the Western Honey Bee, Apis Mellifera. Insects (2020) 11(4):239. doi: 10.3390/insects11040239

24. McMenamin AJ, Flenniken ML. Recently Identified Bee Viruses and Their Impact on Bee Pollinators. Curr Opin Insect Sci (2018) 26:120-9. doi: 10.1016/j.cois.2018.02.009

25. de Miranda JR, Genersch E. Deformed Wing Virus. J Invertebrate Pathol (2010) 103:S48-61. doi: 10.1016/j.jip.2009.06.012

26. Highfield AC, Nagar AE, Mackinder LCM, Noël LM-LJ, Hall MJ, Martin SJ, et al. Deformed Wing Virus Implicated in Overwintering Honeybee Colony Losses. Appl Environ Microbiol (2009) 75(22):7212-20. doi: 10.1128/ AEM.02227-09

27. Faurot-Daniels C, Glenny W, Daughenbaugh KF, McMenamin AJ, Burkle LA, Flenniken ML. Longitudinal Monitoring of Honey Bee Colonies Reveals Dynamic Nature of Virus Abundance and Indicates a Negative Impact of Lake Sinai Virus 2 on Colony Health. PloS One (2020) 15(9):e0237544. doi: 10.1371/journal.pone.0237544

28. Glenny W, Cavigli I, Daughenbaugh KF, Radford R, Kegley SE, Flenniken ML. Honey Bee (Apis Mellifera) Colony Health and Pathogen Composition in Migratory Beekeeping Operations Involved in California Almond Pollination. PloS One (2017) 12(8):e0182814. doi: 10.1371/journal.pone. 0182814

29. D’Alvise P, Seeburger V, Gihring K, Kieboom M, Hasselmann M. Seasonal Dynamics and Co-Occurrence Patterns of Honey Bee Pathogens Revealed by High-Throughput RT-qPCR Analysis. Ecol Evol (2019) 9(18):10241-52. doi: 10.1002/ece3.5544

30. Antúnez K, Anido M, Branchiccela B, Harriet J, Campa J, Invernizzi C, et al. Seasonal Variation of Honeybee Pathogens and Its Association With Pollen Diversity in Uruguay. Microb Ecol (2015) 70(2):522-33. doi: 10.1007/ s00248-015-0594-7

31. Nazzi F, Brown SP, Annoscia D, Del Piccolo F, Di Prisco G, Varricchio P, et al. Synergistic Parasite-Pathogen Interactions Mediated by Host Immunity Can Drive the Collapse of Honeybee Colonies. PloS Pathog (2012) 8(6):e1002735. doi: 10.1371/journal.ppat.1002735

32. Di Prisco G, Annoscia D, Margiotta M, Ferrara R, Varricchio P, Zanni V, et al. A Mutualistic Symbiosis Between a Parasitic Mite and a Pathogenic Virus Undermines Honey Bee Immunity and Health. Proc Natl Acad Sci (2016) 113(12):3203-8. doi: 10.1073/pnas.1523515113

33. Wilfert L, Long G, Leggett H, Schmid-Hempel P, Butlin R, Martin S, et al. Deformed Wing Virus Is a Recent Global Epidemic in Honeybees Driven by Varroa Mites. Science (2016) 351(6273):594-7. doi: 10.1126/science.aac9976

34. Ryabov EV, Wood GR, Fannon JM, Moore JD, Bull JC, Chandler D, et al. A Virulent Strain of Deformed Wing Virus (DWV) of Honeybees (Apis Mellifera) Prevails After Varroa Destructor-Mediated, or In Vitro, Transmission. PloS Pathog (2014) 10(6):e1004230. doi: 10.1371/ journal.ppat.1004230

35. Annoscia D, Del Piccolo F, Covre F, Nazzi F. Mite Infestation During Development Alters the in-Hive Behaviour of Adult Honeybees. Apidologie (2015) 46(3):306-14. doi: 10.1007/s13592-014-0323-0

36. Benaets K, Van Geystelen A, Cardoen D, De Smet L, de Graaf DC, Schoofs L, et al. Covert Deformed Wing Virus Infections Have Long-Term Deleterious Effects on Honeybee Foraging and Survival. Proc R Soc B: Biol Sci (2017) 284 (1848):20162149. doi: 10.1098/rspb.2016.2149 
37. McMenamin AJ, Daughenbaugh KF, Parekh F, Pizzorno MC, Flenniken ML. Honey Bee and Bumble Bee Antiviral Defense. Viruses (2018) 10(8):395. doi: 10.3390/v10080395

38. Lourenço AP, Florecki MM, Simões ZLP, Evans JD. Silencing of Apis Mellifera Dorsal Genes Reveals Their Role in Expression of the Antimicrobial Peptide Defensin-1. Insect Mol Biol (2018) 27(5):577-89. doi: $10.1111 / \mathrm{imb} .12498$

39. Danihlík J, Aronstein K, Petřivalský M. Antimicrobial Peptides: A Key Component of Honey Bee Innate Immunity. J Apicult Res (2015) 54(2):12336. doi: 10.1080/00218839.2015.1109919

40. Brutscher LM, Daughenbaugh KF, Flenniken ML. Antiviral Defense Mechanisms in Honey Bees. Curr Opin Insect Sci (2015) 10:71-82. doi: 10.1016/j.cois.2015.04.016

41. Evans J, Aronstein K, Chen YP, Hetru C, Imler JL, Jiang H, et al. Immune Pathways and Defence Mechanisms in Honey Bees Apis Mellifera. Insect Mol Biol (2006) 15(5):645-56. doi: 10.1111/j.1365-2583.2006.00682.x

42. Flenniken ML, Andino R. Non-Specific dsRNA-Mediated Antiviral Response in the Honey Bee. PloS One (2013) 8(10):e77263. doi: 10.1371/ journal.pone. 0077263

43. Brutscher LM, Daughenbaugh KF, Flenniken ML. Virus and dsRNATriggered Transcriptional Responses Reveal Key Components of Honey Bee Antiviral Defense. Sci Rep (2017) 7(1):1-15. doi: 10.1038/s41598-017-06623-z

44. Chen YP, Pettis JS, Corona M, Chen WP, Li CJ, Spivak M, et al. Israeli Acute Paralysis Virus: Epidemiology, Pathogenesis and Implications for Honey Bee Health. PloS Pathog (2014) 10(7):e1004261. doi: 10.1371/journal.ppat. 1004261

45. Maori E, Paldi N, Shafir S, Kalev H, Tsur E, Glick E, et al. IAPV, a BeeAffecting Virus Associated With Colony Collapse Disorder Can be Silenced by dsRNA Ingestion. Insect Mol Biol (2009) 18(1):55-60. doi: 10.1111/ j.1365-2583.2009.00847.x

46. Piot N, Snoeck S, Vanlede M, Smagghe G, Meeus I. The Effect of Oral Administration of dsRNA on Viral Replication and Mortality in Bombus Terrestris. Viruses (2015) 7(6):3172-85. doi: 10.3390/v7062765

47. Niu J, Smagghe G, De Coninck DI, Van Nieuwerburgh F, Deforce D, Meeus I. In Vivo Study of Dicer-2-Mediated Immune Response of the Small Interfering RNA Pathway Upon Systemic Infections of Virulent and Avirulent Viruses in Bombus Terrestris. Insect Biochem Mol Biol (2016) 70:127-37. doi: 10.1016/j.ibmb.2015.12.006

48. Hammond SM. Dicing and Slicing: The Core Machinery of the RNA Interference Pathway. FEBS Lett (2005) 579(26):5822-9. doi: 10.1016/ j.febslet.2005.08.079

49. Ding S-W. RNA-Based Antiviral Immunity. Nat Rev Immunol (2010) 10 (9):632-44. doi: 10.1038/nri2824

50. Bronkhorst AW, van Rij RP. The Long and Short of Antiviral Defense: Small RNA-Based Immunity in Insects. Curr Opin Virol (2014) 7:19-28. doi: 10.1016/j.coviro.2014.03.010

51. Kingsolver MB, Hardy RW. Making Connections in Insect Innate Immunity. Proc Natl Acad Sci (2012) 109(46):18639-40. doi: 10.1073/ pnas. 1216736109

52. Van Rij RP, Saleh M-C, Berry B, Foo C, Houk A, Antoniewski C, et al. The RNA Silencing Endonuclease Argonaute 2 Mediates Specific Antiviral Immunity in Drosophila Melanogaster. Genes Dev (2006) 20(21):2985-95. doi: 10.1101/gad.1482006

53. Zambon RA, Vakharia VN, Wu LP. RNAi is an Antiviral Immune Response Against a dsRNA Virus in Drosophila Melanogaster. Cell Microbiol (2006) 8 (5):880-9. doi: 10.1111/j.1462-5822.2006.00688.x

54. Parker JS, Barford D. Argonaute: A Scaffold for the Function of Short Regulatory RNAs. Trends Biochem Sci (2006) 31(11):622-30. doi: 10.1016/ j.tibs.2006.09.010

55. Wang X-H, Aliyari R, Li W-X, Li H-W, Kim K, Carthew R, et al. RNA Interference Directs Innate Immunity Against Viruses in Adult Drosophila. Science (2006) 312(5772):452-4. doi: 10.1126/science.1125694

56. Galiana-Arnoux D, Dostert C, Schneemann A, Hoffmann JA, Imler J-L. Essential Function In Vivo for Dicer-2 in Host Defense Against RNA Viruses in Drosophila. Nat Immunol (2006) 7(6):590-7. doi: 10.1038/ni1335

57. Galbraith DA, Yang X, Niño EL, Yi S, Grozinger C. Parallel Epigenomic and Transcriptomic Responses to Viral Infection in Honey Bees (Apis Mellifera). PloS Pathog (2015) 11(3):e1004713. doi: 10.1371/journal.ppat.1004713
58. Chejanovsky N, Ophir R, Schwager MS, Slabezki Y, Grossman S, Cox-Foster D. Characterization of Viral siRNA Populations in Honey Bee Colony Collapse Disorder. Virology (2014) 454-455:176-83. doi: 10.1016/j.virol. 2014.02.012

59. Desai S, Eu YJ, Whyard S, Currie R. Reduction in Deformed Wing Virus Infection in Larval and Adult Honey Bees (Apis Mellifera L.) by DoubleStranded RNA Ingestion. Insect Mol Biol (2012) 21(4):446-55. doi: 10.1111/ j.1365-2583.2012.01150.x

60. Merkling SH, Overheul GJ, van Mierlo JT, Arends D, Gilissen C, van Rij RP. The Heat Shock Response Restricts Virus Infection in Drosophila. Sci Rep (2015) 5(1):12758. doi: 10.1038/srep12758

61. McMenamin AJ, Daughenbaugh KF, Flenniken ML. The Heat Shock Response in the Western Honey Bee (Apis Mellifera) Is Antiviral. Viruses (2020) 12(2):245. doi: 10.3390/v12020245

62. McKinstry M, Chung C, Truong H, Johnston BA, Snow JW. The Heat Shock Response and Humoral Immune Response Are Mutually Antagonistic in Honey Bees. Sci Rep (2017) 7(1):8850. doi: 10.1038/s41598-017-09159-4

63. Kampmueller KM, Miller DJ. The Cellular Chaperone Heat Shock Protein 90 Facilitates Flock House Virus RNA Replication in Drosophila Cells. J Virol (2005) 79(11):6827-37. doi: 10.1128/jvi.79.11.6827-6837.2005

64. Glotzer JB, Saltik M, Chiocca S, Michou AI, Moseley P, Cotten M. Activation of Heat-Shock Response by an Adenovirus Is Essential for Virus Replication. Nature (2000) 407(6801):207-11. doi: 10.1038/35025102

65. Dalmon A, Peruzzi M, Le Conte Y, Alaux C, Pioz M. Temperature-Driven Changes in Viral Loads in the Honey Bee Apis Mellifera. J Invertebrate Pathol (2019) 160:87-94. doi: 10.1016/j.jip.2018.12.005

66. Ryabov EV, Fannon JM, Moore JD, Wood GR, Evans DJ. The Iflaviruses Sacbrood Virus and Deformed Wing Virus Evoke Different Transcriptional Responses in the Honeybee Which May Facilitate Their Horizontal or Vertical Transmission. PeerJ (2016) 4:e1591. doi: 10.7717/peerj.1591

67. Li Z, Zhang S, Zhang J, Liu M, Liu Z. Vitellogenin Is a Cidal Factor Capable of Killing Bacteria via Interaction With Lipopolysaccharide and Lipoteichoic Acid. Mol Immunol (2009) 46(16):3232-9. doi: 10.1016/j.molimm.2009. 08.006

68. Li Z, Zhang S, Liu Q. Vitellogenin Functions as a Multivalent Pattern Recognition Receptor With an Opsonic Activity. PloS One (2008) 3(4): e1940. doi: 10.1371/journal.pone.0001940

69. Salmela H, Amdam GV, Freitak D. Transfer of Immunity From Mother to Offspring Is Mediated via Egg-Yolk Protein Vitellogenin. PloS Pathog (2015) 11(7):e1005015. doi: 10.1371/journal.ppat.1005015

70. Amdam GV, Omholt SW. The Regulatory Anatomy of Honeybee Lifespan. J Theor Biol (2002) 216(2):209-28. doi: 10.1006/jtbi.2002.2545

71. Amdam GV, Fennern E, Havukainen H. Vitellogenin in Honey Bee Behavior and Lifespan. In: CG Galizia, D Eisenhardt and M Giurfa, editors. Honeybee Neurobiology and Behavior: A Tribute to Randolf Menzel. Dordrecht: Springer Netherlands (2012). p. 17-29.

72. Corona M, Velarde RA, Remolina S, Moran-Lauter A, Wang Y, Hughes KA, et al. Vitellogenin, Juvenile Hormone, Insulin Signaling, and Queen Honey Bee Longevity. Proc Natl Acad Sci (2007) 104(17):7128-33. doi: 10.1073/ pnas.0701909104

73. Seehuus S-C, Norberg K, Gimsa U, Krekling T, Amdam GV. Reproductive Protein Protects Functionally Sterile Honey Bee Workers From Oxidative Stress. Proc Natl Acad Sci USA (2006) 103(4):962-7. doi: 10.1073/ pnas. 0502681103

74. Marco Antonio DS, Guidugli-Lazzarini KR, do Nascimento AM, Simões ZLP, Hartfelder K. RNAi-Mediated Silencing of Vitellogenin Gene Function Turns Honeybee (Apis Mellifera) Workers Into Extremely Precocious Foragers. Naturwissenschaften (2008) 95(10):953-61. doi: 10.1007/s00114008-0413-9

75. Münch D, Amdam G, Wolschin F. Ageing in a Eusocial Insect: Molecular and Physiological Characteristics of Life Span Plasticity in the Honey Bee. Funct Ecol (2008) 22(3):407-21. doi: 10.1111/j.1365-2435.2008.01419.x

76. Pluta P, Sokół R. Changes in the Expression of Antimicrobial Peptide Genes in Honey Bees (Apis Mellifera) Under the Influence of Various Pathogens. Ann Parasitol (2020) 66(4):457-65. doi: 10.17420/ap6604.286

77. Page RE, Rueppell O, Amdam GV. Genetics of Reproduction and Regulation of Honeybee (Apis Mellifera L.) Social Behavior. Annu Rev Genet (2012) 46 (1):97-119. doi: 10.1146/annurev-genet-110711-155610 
78. Dainat B, Evans JD, Chen YP, Gauthier L, Neumann P. Predictive Markers of Honey Bee Colony Collapse. PloS One (2012) 7(2):e32151. doi: 10.1371/ journal.pone.0032151

79. Smart M, Pettis J, Rice N, Browning Z, Spivak M. Linking Measures of Colony and Individual Honey Bee Health to Survival Among Apiaries Exposed to Varying Agricultural Land Use. PloS One (2016) 11(3): e0152685. doi: 10.1371/journal.pone.0152685

80. Zanni V, Galbraith DA, Annoscia D, Grozinger CM, Nazzi F. Transcriptional Signatures of Parasitization and Markers of Colony Decline in Varroa-Infested Honey Bees (Apis Mellifera). Insect Biochem Mol Biol (2017) 87:1-13. doi: 10.1016/j.ibmb.2017.06.002

81. Carrillo-Tripp J, Dolezal AG, Goblirsch MJ, Miller WA, Toth AL, Bonning BC. In Vivo and In Vitro Infection Dynamics of Honey Bee Viruses. Sci Rep (2016) 6(1):22265. doi: 10.1038/srep22265

82. Lamp B, Url A, Seitz K, Eichhorn J, Riedel C, Sinn LJ, et al. Construction and Rescue of a Molecular Clone of Deformed Wing Virus (DWV). PloS One (2016) 11(11):e0164639. doi: 10.1371/journal.pone.0164639

83. Ryabov EV, Christmon K, Heerman MC, Posada-Florez F, Harrison RL, Chen Y, et al. Development of a Honey Bee RNA Virus Vector Based on the Genome of a Deformed Wing Virus. Viruses (2020) 12(4):374. doi: 10.3390/v12040374

84. Seitz K, Buczolich K, Dikunová A, Plevka P, Power K, Rümenapf T, et al. A Molecular Clone of Chronic Bee Paralysis Virus (CBPV) Causes Mortality in Honey Bee Pupae (Apis Mellifera). Sci Rep (2019) 9(1):16274. doi: 10.1038/ s41598-019-52822-1

85. O'Neal ST, Swale DR, Anderson TD. ATP-Sensitive Inwardly Rectifying Potassium Channel Regulation of Viral Infections in Honey Bees. Sci Rep (2017) 7(1):1-9. doi: 10.1038/s41598-017-09448-y

86. Dasgupta R, Free HM, Zietlow SL, Paskewitz SM, Aksoy S, Shi L, et al. Replication of Flock House Virus in Three Genera of Medically Important Insects. J Med Entomol (2007) 44(1):102-10. doi: 10.1093/jmedent/41.5.102

87. Dasgupta R, Cheng L-L, Bartholomay LC, Christensen BM. Flock House Virus Replicates and Expresses Green Fluorescent Protein in Mosquitoes. J Gen Virol (2003) 84(7):1789-97. doi: 10.1099/vir.0.18938-0

88. Dearing SC, Scotti PD, Wigley PJ, Dhana SD. A Small RNA Virus Isolated From the Grass Grub, Costelytra Zealandica (Coleoptera: Scarabaeidae). New Z J Zool (1980) 7(2):267-9. doi: 10.1080/03014223.1980.10423785

89. R Dasgupta, B Selling and R Rueckert eds. Flock House Virus: A Simple Model for Studying Persistent Infection in Cultured Drosophila Cells. Vienna: Springer Vienna (1994).

90. Taning CNT, Christiaens O, Li X, Swevers L, Casteels H, Maes M, et al. Engineered Flock House Virus for Targeted Gene Suppression Through RNAi in Fruit Flies (Drosophila Melanogaster) In Vitro and In Vivo. Front Physiol (2018) 9:805(805). doi: 10.3389/fphys.2018.00805

91. Scotti PD, Dearing S, Mossop DW. Flock House Virus: A Nodavirus Isolated From Costelytra Zealandica (White) (Coleoptera: Scarabaeida). Arch Virol (1983) 75(3):181-9. doi: 10.1007/BF01315272

92. Bonning BC, Saleh M-C. The Interplay Between Viruses and RNAi Pathways in Insects. Annu Rev Entomol (2021) 66(1):61-79. doi: 10.1146/annurevento-033020-090410

93. Saleh M-C, Tassetto M, Van Rij RP, Goic B, Gausson V, Berry B, et al. Antiviral Immunity in Drosophila Requires Systemic RNA Interference Spread. Nature (2009) 458(7236):346-50. doi: 10.1038/nature07712

94. Nayak A, Berry B, Tassetto M, Kunitomi M, Acevedo A, Deng C, et al. Cricket Paralysis Virus Antagonizes Argonaute 2 to Modulate Antiviral Defense in Drosophila. Nat Struct Mol Biol (2010) 17(5):547-54. doi: $10.1038 / \mathrm{nsmb} .1810$

95. Kemp C, Imler J-L. Antiviral Immunity in Drosophila. Curr Opin Immunol (2009) 21(1):3-9. doi: 10.1016/j.coi.2009.01.007

96. Blair CD. Mosquito RNAi is the Major Innate Immune Pathway Controlling Arbovirus Infection and Transmission. Future Microbiol (2011) 6(3):265-77. doi: $10.2217 / \mathrm{fmb} .11 .11$

97. Alaux C, Ducloz F, Crauser D, Le Conte Y. Diet Effects on Honeybee Immunocompetence. Biol Lett (2010) 6(4):562-5. doi: 10.1098/rsbl. 2009.0986

98. Dolezal AG, Carrillo-Tripp J, Judd TM, Allen Miller W, Bonning BC, Toth AL. Interacting Stressors Matter: Diet Quality and Virus Infection in Honeybee Health. R Soc Open Sci (2019) 6(2):181803. doi: 10.1098/ rsos. 181803
99. Negri P, Villalobos E, Szawarski N, Damiani N, Gende L, Garrido M, et al. Towards Precision Nutrition: A Novel Concept Linking Phytochemicals, Immune Response and Honey Bee Health. Insects (2019) 10(11):401. doi: 10.3390/insects10110401

100. DeGrandi-Hoffman G, Chen Y. Nutrition, Immunity and Viral Infections in Honey Bees. Curr Opin Insect Sci (2015) 10:170-6. doi: 10.1016/ j.cois.2015.05.007

101. Brodschneider R, Crailsheim K. Nutrition and Health in Honey Bees*. Apidologie (2010) 41(3):278-94. doi: 10.1051/apido/2010012

102. Drescher N, Klein A-M, Schmitt T. Leonhardt SD. A Clue on Bee Glue: New Insight Into the Sources and Factors Driving Resin Intake in Honeybees (Apis Mellifera). PloS One (2019) 14(2):e0210594. doi: 10.1371/journal. pone. 0210594

103. Tauber JP, Collins WR, Schwarz RS, Chen Y, Grubbs K, Huang Q, et al. Natural Product Medicines for Honey Bees: Perspective and Protocols. Insects (2019) 10(10):356. doi: 10.3390/insects 10100356

104. Palmer-Young EC, Tozkar CÖ, Schwarz RS, Chen Y, Irwin RE, Adler LS, et al. Nectar and Pollen Phytochemicals Stimulate Honey Bee (Hymenoptera: Apidae) Immunity to Viral Infection. J Economic Entomol (2017) 110 (5):1959-72. doi: 10.1093/jee/tox193

105. Strachecka A, Krauze M, Olszewski K, Borsuk G, Paleolog J, Merska M, et al. Unexpectedly Strong Effect of Caffeine on the Vitality of Western Honeybees (Apis Mellifera). Biochem (Moscow) (2014) 79(11):1192-201. doi: 10.1134/ S0006297914110066

106. Negri P, Ramirez L, Quintana S, Szawarski N, Maggi MD, Eguaras MJ, et al. Immune-Related Gene Expression of Apis Mellifera Larvae in Response to Cold Stress and Abscisic Acid (ABA) Dietary Supplementation. J Apicult Res (2020) 59(4):669-76. doi: 10.1080/00218839.2019.1708653

107. Mao W, Schuler MA, Berenbaum MR. Honey Constituents Up-Regulate Detoxification and Immunity Genes in the Western Honey Bee Apis Mellifera. Proc Natl Acad Sci (2013) 110(22):8842-6. doi: 10.1073/pnas.1303884110

108. Wiese N, Fischer J, Heidler J, Lewkowski O, Degenhardt J, Erler S. The Terpenes of Leaves, Pollen, and Nectar of Thyme (Thymus Vulgaris) Inhibit Growth of Bee Disease-Associated Microbes. Sci Rep (2018) 8(1):14634. doi: 10.1038/s41598-018-32849-6

109. Palmer-Young EC, Sadd BM, Stevenson PC, Irwin RE, Adler LS. Bumble Bee Parasite Strains Vary in Resistance to Phytochemicals. Sci Rep (2016) 6 (1):37087. doi: 10.1038/srep37087

110. Rennich K, Pettis J, VanEngelsdorp D, Bozarth R, Eversole H, Roccasecca K, et al. 2011-2012 National Honey Bee Pests and Diseases Survey Report. USDA Anim Plant Health Inspect (2012).

111. Nozal MJ, Bernal JL, Jiménez JJ, González MJ, Higes M. Extraction of Thymol, Eucalyptol, Menthol, and Camphor Residues From Honey and Beeswax: Determination by Gas Chromatography With Flame Ionization Detection. J Chromatogr A (2002) 954(1):207-15. doi: 10.1016/S0021-9673 (02)00153-X

112. Šegvić Klarić M, Kosalec I, Mastelić J, Piecková E, Pepeljnak S. Antifungal Activity of Thyme (Thymus Vulgaris L.) Essential Oil and Thymol Against Moulds From Damp Dwellings. Lett Appl Microbiol (2007) 44(1):36-42. doi: 10.1111/j.1472-765X.2006.02032.x

113. McGimpsey JA, Douglas MH, Van Klink JW, Beauregard DA, Perry NB. Seasonal Variation in Essential Oil Yield and Composition From Naturalized Thymus Vulgaris L. @ in New Zealand. Flavour Fragrance J (1994) 9(6):34752. doi: $10.1002 / \mathrm{ffj} .2730090613$

114. Burt S. Essential Oils: Their Antibacterial Properties and Potential Applications in Foods-a Review. Int J Food Microbiol (2004) 94(3):22353. doi: 10.1016/j.ijfoodmicro.2004.03.022

115. Lens-Lisbonne C, Cremieux A, Maillard C, Balansard G. Methodes D'evaluation De L'activite Antibacterienne Des Huiles Essentielles: Application Aux Essences De Thym Et De Cannelle. J Pharm Belg (1987) 42(5):297-302.

116. Arras G, Grella GE. Wild Thyme, Thymus Capitatus, Essential Oil Seasonal Changes and Antimycotic Activity. J Hortic Sci (1992) 67(2):197-202. doi: 10.1080/00221589.1992.11516237

117. Cosentino S, Tuberoso CIG, Pisano B, Satta M, Mascia V, Arzedi E, et al. InVitro Antimicrobial Activity and Chemical Composition of Sardinian Thymus Essential Oils. Lett Appl Microbiol (1999) 29(2):130-5. doi: 10.1046/j.1472-765X.1999.00605.x 
118. Juliano C, Mattana A, Usai M. Composition and In Vitro Antimicrobial Activity of the Essential Oil of Thymus Herba-Barona Loisel Growing Wild in Sardinia. J Essential Oil Res (2000) 12(4):516-22. doi: 10.1080/ 10412905.2000.9699578

119. Gregorc A, Planinc I. The Control of Varroa Destructor in Honey Bee Colonies Using the Thymol-Based Acaricide-Apiguard. Am Bee J (2005) 145 (8):672-5.

120. Floris I, Satta A, Cabras P, Garau VL, Angioni A. Comparison Between Two Thymol Formulations in the Control of Varroa Destructor: Effectiveness, Persistence, and Residues. J Economic Entomol (2004) 97(2):187-91. doi: 10.1093/jee/97.2.187

121. Chen Y, Evans JD, Smith IB, Pettis JS. Nosema Ceranae Is a Long-Present and Wide-Spread Microsporidian Infection of the European Honey Bee (Apis Mellifera) in the United States. J Invertebrate Pathol (2008) 97(2):1868. doi: 10.1016/j.jip.2007.07.010

122. Klee J, Besana AM, Genersch E, Gisder S, Nanetti A, Tam DQ, et al. Widespread Dispersal of the Microsporidian Nosema Ceranae, an Emergent Pathogen of the Western Honey Bee, Apis Mellifera. J Invertebrate Pathol (2007) 96(1):1-10. doi: 10.1016/j.jip.2007.02.014

123. Richardson LL, Adler LS, Leonard AS, Andicoechea J, Regan KH, Anthony WE, et al. Secondary Metabolites in Floral Nectar Reduce Parasite Infections in Bumblebees. Proc R Soc B: Biol Sci (2015) 282(1803):20142471. doi: 10.1098/rspb.2014.2471

124. Costa C, Lodesani M, Maistrello L. Effect of Thymol and Resveratrol Administered With Candy or Syrup on the Development of Nosema Ceranae and on the Longevity of Honeybees (Apis Mellifera L.) in Laboratory Conditions*. Apidologie (2010) 41(2):141-50. doi: 10.1051/ apido/2009070

125. Krupke CH, Hunt GJ, Eitzer BD, Andino G, Given K. Multiple Routes of Pesticide Exposure for Honey Bees Living Near Agricultural Fields. PloS One (2012) 7(1):e29268. doi: 10.1371/journal.pone.0029268

126. Krupke CH, Holland JD, Long EY, Eitzer BD. Planting of NeonicotinoidTreated Maize Poses Risks for Honey Bees and Other Non-Target Organisms Over a Wide Area Without Consistent Crop Yield Benefit. J Appl Ecol (2017) 54(5):1449-58. doi: 10.1111/1365-2664.12924

127. Jeschke P, Nauen R. Neonicotinoids-from Zero to Hero in Insecticide Chemistry. Pest Manage Sci: Formerly Pesticide Sci (2008) 64(11):1084-98. doi: $10.1002 / p s .1631$

128. Cabirol A, Haase A. The Neurophysiological Bases of the Impact of Neonicotinoid Pesticides on the Behaviour of Honeybees. Insects (2019) 10 (10):344. doi: 10.3390/insects10100344

129. Matsuda K, Buckingham SD, Kleier D, Rauh JJ, Grauso M, Sattelle DB. Neonicotinoids: Insecticides Acting on Insect Nicotinic Acetylcholine Receptors. Trends Pharmacol Sci (2001) 22(11):573-80. doi: 10.1016/ S0165-6147(00)01820-4

130. Laurino D, Manino A, Patetta A, Porporato M. Toxicity of Neonicotinoid Insecticides on Different Honey Bee Genotypes. Journal- Bulletin of Insectology (2013) 66:119-136.

131. Iwasa T, Motoyama N, Ambrose JT, Roe RM. Mechanism for the Differential Toxicity of Neonicotinoid Insecticides in the Honey Bee, Apis Mellifera. Crop Prot (2004) 23(5):371-8. doi: 10.1016/j.cropro.2003.08.018

132. Decourtye A, Devillers J. Ecotoxicity of Neonicotinoid Insecticides to Bees. In: SH Thany, editor. Insect Nicotinic Acetylcholine Receptors. New York, NY: Springer (2010) 683:85-95. doi: 10.1007/978-1-4419-6445-8_8

133. Mullin CA, Frazier M, Frazier JL, Ashcraft S, Simonds R, vanEngelsdorp D, et al. High Levels of Miticides and Agrochemicals in North American Apiaries: Implications for Honey Bee Health. PloS One (2010) 5(3):e9754. doi: 10.1371/journal.pone.0009754

134. Wu JY, Anelli CM, Sheppard WS. Sub-Lethal Effects of Pesticide Residues in Brood Comb on Worker Honey Bee (Apis Mellifera) Development and Longevity. PloS One (2011) 6(2):e14720. doi: 10.1371/journal.pone.0014720

135. Rundlöf M, Andersson GKS, Bommarco R, Fries I, Hederström V, Herbertsson L, et al. Seed Coating With a Neonicotinoid Insecticide Negatively Affects Wild Bees. Nature (2015) 521(7550):77-80. doi: 10.1038 /nature 14420

136. Sanchez-Bayo F, Goka K. Pesticide Residues and Bees - A Risk Assessment. PloS One (2014) 9(4):e94482. doi: 10.1371/journal.pone.0094482
137. Bonmatin JM, Giorio C, Girolami V, Goulson D, Kreutzweiser DP, Krupke C, et al. Environmental Fate and Exposure; Neonicotinoids and Fipronil. Environ Sci Pollut Res (2015) 22(1):35-67. doi: 10.1007/s11356-014-3332-7

138. Botías C, David A, Horwood J, Abdul-Sada A, Nicholls E, Hill E, et al. Neonicotinoid Residues in Wildflowers, a Potential Route of Chronic Exposure for Bees. Environ Sci Technol (2015) 49(21):12731-40. doi: 10.1021/acs.est.5b03459

139. Johnson RM, Ellis MD, Mullin CA, Frazier M. Pesticides and Honey Bee Toxicity - USA*. Apidologie (2010) 41(3):312-31. doi: 10.1051/apido/ 2010018

140. Cutler CG, Scott-Dupree CD. Exposure to Clothianidin Seed-Treated Canola Has No Long-Term Impact on Honey Bees. J Economic Entomol (2007) 100 (3):765-72. doi: 10.1093/jee/100.3.765

141. Morfin N, Goodwin PH, Correa-Benitez A, Guzman-Novoa E. Sublethal Exposure to Clothianidin During the Larval Stage Causes Long-Term Impairment of Hygienic and Foraging Behaviours of Honey Bees. Apidologie (2019) 50(5):595-605. doi: 10.1007/s13592-019-00672-1

142. Morfin N, Goodwin PH, Guzman-Novoa E. Interaction of Field Realistic Doses of Clothianidin and Varroa Destructor Parasitism on Adult Honey Bee (Apis Mellifera L.) Health and Neural Gene Expression, and Antagonistic Effects on Differentially Expressed Genes. PloS One (2020) 15 (2):e0229030. doi: 10.1371/journal.pone.0229030

143. Morfin N, Goodwin PH, Hunt GJ, Guzman-Novoa E. Effects of Sublethal Doses of Clothianidin and/or V. Destructor on Honey Bee (Apis Mellifera) Self-Grooming Behavior and Associated Gene Expression. Sci Rep (2019) 9 (1):5196. doi: 10.1038/s41598-019-41365-0

144. Abdelkader FB, Kairo G, Bonnet M, Barbouche N, Belzunces LP, Brunet JL. Effects of Clothianidin on Antioxidant Enzyme Activities and Malondialdehyde Level in Honey Bee Drone Semen. J Apicult Res (2019) 58(5):740-5. doi: 10.1080/00218839.2019.1655182

145. Matsumoto T. Reduction in Homing Flights in the Honey Bee Apis Mellifera After a Sublethal Dose of Neonicotinoid Insecticides. Bull Insectol (2013) 66 (1):1-9.

146. Tison L, Duer A, Púčiková V, Greggers U, Menzel R. Detrimental Effects of Clothianidin on Foraging and Dance Communication in Honey Bees. PloS One (2020) 15(10):e0241134. doi: 10.1371/journal.pone.0241134

147. Samson-Robert O, Labrie G, Chagnon M, Fournier V. Planting of Neonicotinoid-Coated Corn Raises Honey Bee Mortality and Sets Back Colony Development. PeerJ (2017) 5:e3670. doi: 10.7717/peerj.3670

148. Tsvetkov N, Samson-Robert O, Sood K, Patel HS, Malena DA, Gajiwala PH, et al. Chronic Exposure to Neonicotinoids Reduces Honey Bee Health Near Corn Crops. Science (2017) 356(6345):1395-7. doi: 10.1126/science.aam7470

149. Zhu YC, Adamczyk J, Rinderer T, Yao J, Danka R, Luttrell R, et al. Spray Toxicity and Risk Potential of 42 Commonly Used Formulations of Row Crop Pesticides to Adult Honey Bees (Hymenoptera: Apidae). J Economic Entomol (2015) 108(6):2640-7. doi: 10.1093/jee/tov269

150. Brandt A, Gorenflo A, Siede R, Meixner M, Büchler R. The Neonicotinoids Thiacloprid, Imidacloprid, and Clothianidin Affect the Immunocompetence of Honey Bees (Apis Mellifera L.). J Insect Physiol (2016) 86:40-7. doi: 10.1016/j.jinsphys.2016.01.001

151. Sánchez-Bayo F, Goulson D, Pennacchio F, Nazzi F, Goka K, Desneux N. Are Bee Diseases Linked to Pesticides? - A Brief Review. Environ Int (2016) 8990:7-11. doi: 10.1016/j.envint.2016.01.009

152. Nazzi F, Pennacchio F. Honey Bee Antiviral Immune Barriers as Affected by Multiple Stress Factors: A Novel Paradigm to Interpret Colony Health Decline and Collapse. Viruses (2018) 10(4). doi: 10.3390/v10040159

153. DeGrandi-Hoffman G, Chen Y, Simonds R. The Effects of Pesticides on Queen Rearing and Virus Titers in Honey Bees (Apis Mellifera L.). Insects (2013) 4(1):71-89. doi: 10.3390/insects4010071

154. Di Prisco G, Cavaliere V, Annoscia D, Varricchio P, Caprio E, Nazzi F, et al. Neonicotinoid Clothianidin Adversely Affects Insect Immunity and Promotes Replication of a Viral Pathogen in Honey Bees. Proc Natl Acad Sci (2013) 110(46):18466-71. doi: 10.1073/pnas.1314923110

155. Alburaki M, Boutin S, Mercier P-L, Loublier Y, Chagnon M, Derome N. Neonicotinoid-Coated Zea Mays Seeds Indirectly Affect Honeybee Performance and Pathogen Susceptibility in Field Trials. PloS One (2015) 10(5):e0125790. doi: 10.1371/journal.pone.0125790 
156. Doublet V, Labarussias M, de Miranda JR, Moritz RF, Paxton RJ. Bees Under Stress: Sublethal Doses of a Neonicotinoid Pesticide and Pathogens Interact to Elevate Honey Bee Mortality Across the Life Cycle. Environ Microbiol (2015) 17(4):969-83. doi: 10.1111/1462-2920.12426

157. Coulon M, Schurr F, Martel A-C, Cougoule N, Bégaud A, Mangoni P, et al. Influence of Chronic Exposure to Thiamethoxam and Chronic Bee Paralysis Virus on Winter Honey Bees. PloS One (2019) 14(8):e0220703. doi: 10.1371/ journal.pone. 0220703

158. Bailey L. The Treatment of Nosema Disease With Fumagillin. Bee World (1953) 34(7):136-7. doi: 10.1080/0005772X.1953.11094806

159. Higes M, Nozal MJ, Alvaro A, Barrios L, Meana A, Martín-Hernández R, et al. The Stability and Effectiveness of Fumagillin in Controlling Nosema Ceranae (Microsporidia) Infection in Honey Bees (Apis Mellifera) Under Laboratory and Field Conditions. Apidologie (2011) 42(3):364-77. doi: 10.1007/s13592-011-0003-2

160. Didier ES. Effects of Albendazole, Fumagillin, and TNP-470 on Microsporidial Replication In Vitro. Antimicrob Agents Chemother (1997) 41(7):1541-6. doi: 10.1128/AAC.41.7.1541

161. Pajuelo AG, Torres C, Bermejo FJO. Colony Losses: A Double Blind Trial on the Influence of Supplementary Protein Nutrition and Preventative Treatment With Fumagillin Against Nosema Ceranae. J Apicult Res (2008) 47(1):84-6. doi: 10.1080/00218839.2008.11101429

162. Williams GR, Shutler D, Little CM, Burgher-Maclellan KL, Rogers REL. The Microsporidian Nosema Ceranae, the Antibiotic Fumagilin- $\mathrm{B}^{\circledR}$, and Western Honey Bee (Apis Mellifera) Colony Strength. Apidologie (2011) 42(1):15-22. doi: 10.1051/apido/2010030

163. Williams GR, Sampson MA, Shutler D, Rogers REL. Does Fumagillin Control the Recently Detected Invasive Parasite Nosema Ceranae in Western Honey Bees (Apis Mellifera)? J Invertebrate Pathol (2008) 99 (3):342-4. doi: 10.1016/j.jip.2008.04.005

164. Huang W-F, Solter LF, Yau PM, Imai BS. Nosema Ceranae Escapes Fumagillin Control in Honey Bees. PloS Pathog (2013) 9(3):e1003185. doi: 10.1371/journal.ppat.1003185

165. Lopez MI, Pettis JS, Smith IB, Chu P-S. Multiclass Determination and Confirmation of Antibiotic Residues in Honey Using LC-Ms/MS. J Agric Food Chem (2008) 56(5):1553-9. doi: 10.1021/jf073236w

166. Webster TC. Fumagillin Affects Nosema Apis and Honey Bees (Hymonopterai Apidae). J Economic Entomol (1994) 87(3):601-4. doi: 10.1093/jee/87.3.601

167. Rada V, Máchová M, Huk J, Marounek M, Dušková D. Microflora in the Honeybee Digestive Tract: Counts, Characteristics and Sensitivity to Veterinary Drugs. Apidologie (1997) 28(6):357-65. doi: 10.1051/ apido:19970603

168. van den Heever JP, Thompson TS, Otto SJG, Curtis JM, Ibrahim A, Pernal SF. The Effect of Dicyclohexylamine and Fumagillin on Nosema CeranaeInfected Honey Bee (Apis Mellifera) Mortality in Cage Trial Assays. Apidologie (2016) 47(5):663-70. doi: 10.1007/s13592-015-0411-9

169. Miyoshi T, Takeuchi A, Siomi H, Siomi MC. A Direct Role for Hsp90 in PreRISC Formation in Drosophila. Nat Struct Mol Biol (2010) 17(8):1024-6. doi: $10.1038 / \mathrm{nsmb} .1875$

170. Zhao R, Houry WA. Hsp90: A Chaperone for Protein Folding and Gene Regulation. Biochem Cell Biol (2005) 83(6):703-10. doi: 10.1139/o05-158\% M16333321

171. Aquino DA, Peng D, Lopez C, Farooq M. The Constitutive Heat Shock Protein-70 Is Required for Optimal Expression of Myelin Basic Protein During Differentiation of Oligodendrocytes. Neurochem Res (1998) 23 (3):413-20. doi: 10.1023/A:1022473904335

172. Liu T, Daniels CK, Cao S. Comprehensive Review on the HSC70 Functions, Interactions With Related Molecules and Involvement in Clinical Diseases and Therapeutic Potential. Pharmacol Ther (2012) 136(3):354-74. doi: 10.1016/j.pharmthera.2012.08.014

173. Iwasaki S, Kobayashi M, Yoda M, Sakaguchi Y, Katsuma S, Suzuki T, et al. Hsc70/Hsp90 Chaperone Machinery Mediates ATP-Dependent RISC Loading of Small RNA Duplexes. Mol Cell (2010) 39(2):292-9. doi: 10.1016/j.molcel.2010.05.015

174. Lourenço AP, Guidugli-Lazzarini KR, Freitas FCP, Bitondi MMG, Simões ZLP. Bacterial Infection Activates the Immune System Response and
Dysregulates microRNA Expression in Honey Bees. Insect Biochem Mol Biol (2013) 43(5):474-82. doi: 10.1016/j.ibmb.2013.03.001

175. Schlüns H, Crozier R. Relish Regulates Expression of Antimicrobial Peptide Genes in the Honeybee, Apis Mellifera, Shown by RNA Interference. Insect Mol Biol (2007) 16(6):753-9. doi: 10.1111/j.1365-2583.2007.00768.x

176. Gätschenberger H, Azzami K, Tautz J, Beier H. Antibacterial Immune Competence of Honey Bees (Apis Mellifera) Is Adapted to Different Life Stages and Environmental Risks. PloS One (2013) 8(6):e66415. doi: 10.1371/ journal.pone. 0066415

177. Spivak M, Reuter GS. Resistance to American Foulbrood Disease by Honey Bee Colonies Apis Mellifera Bred for Hygienic Behavior. Apidologie (2001) 32(6):555-65. doi: 10.1051/apido:2001103

178. Di Pasquale G, Salignon M, Le Conte Y, Belzunces LP, Decourtye A, Kretzschmar A, et al. Influence of Pollen Nutrition on Honey Bee Health: Do Pollen Quality and Diversity Matter? PloS One (2013) 8(8):e72016. doi: 10.1371/journal.pone.0072016

179. Pritchard DJ. Grooming by Honey Bees as a Component of Varroa Resistant Behavior. J Apicult Res (2016) 55(1):38-48. doi: 10.1080/00218839.2016.1196016

180. Sandrock C, Tanadini M, Tanadini LG, Fauser-Misslin A, Potts SG, Neumann P. Impact of Chronic Neonicotinoid Exposure on Honeybee Colony Performance and Queen Supersedure. PloS One (2014) 9(8): e103592. doi: 10.1371/journal.pone.0103592

181. Wade A, Lin C-H, Kurkul C, Regan ER, Johnson RM. Combined Toxicity of Insecticides and Fungicides Applied to California Almond Orchards to Honey Bee Larvae and Adults. Insects (2019) 10(1):20. doi: 10.3390/ insects 10010020

182. Shi J, Liao C, Wang Z, Zeng Z, Wu X. Effects of Sublethal Acetamiprid Doses on the Lifespan and Memory-Related Characteristics of Honey Bee (Apis Mellifera) Workers. Apidologie (2019) 50(4):553-63. doi: 10.1007/s13592019-00669-w

183. Annoscia D, Di Prisco G, Becchimanzi A, Caprio E, Frizzera D, Linguadoca A, et al. Neonicotinoid Clothianidin Reduces Honey Bee Immune Response and Contributes to Varroa Mite Proliferation. Nat Commun (2020) 11 (1):5887. doi: 10.1038/s41467-020-19715-8

184. Cutler GC. Insects, Insecticides and Hormesis: Evidence and Considerations for Study. Dose-Response (2013) 11(2):154-177. doi: 10.2203/doseresponse.12-008.Cutler. dose-response.12-008.Cutler.

185. Guedes RNC, Cutler GC. Insecticide-Induced Hormesis and Arthropod Pest Management. Pest Manage Sci (2014) 70(5):690-7. doi: 10.1002/ps.3669

186. Cutler GC, Rix RR. Can Poisons Stimulate Bees? Appreciating the Potential of Hormesis in Bee-Pesticide Research. Pest Manage Sci (2015) 71(10):136870. doi: $10.1002 /$ ps.4042

187. Cohen E. Pesticide-Mediated Homeostatic Modulation in Arthropods. Pesticide Biochem Physiol (2006) 85(1):21-7. doi: 10.1016/j.pestbp.2005.09.002

188. Fine JD, Cox-Foster DL, Mullin CA. An Inert Pesticide Adjuvant Synergizes Viral Pathogenicity and Mortality in Honey Bee Larvae. Sci Rep (2017) 7 (1):40499. doi: 10.1038/srep40499

189. O'Neal ST, Anderson TD, Wu-Smart JY. Interactions Between Pesticides and Pathogen Susceptibility in Honey Bees. Curr Opin Insect Sci (2018) 26:57-62. doi: $10.1016 /$ j.cois. 2018.01 .006

190. Vaudo AD, Tooker JF, Grozinger CM, Patch HM. Bee Nutrition and Floral Resource Restoration. Curr Opin Insect Sci (2015) 10:133-41. doi: 10.1016/ j.cois.2015.05.008

191. Goulson D, Nicholls E, Botías C, Rotheray EL. Bee Declines Driven by Combined Stress From Parasites, Pesticides, and Lack of Flowers. Science (2015) 347(6229):1255957. doi: 10.1126/science.1255957

192. Collison E, Hird H, Cresswell J, Tyler C. Interactive Effects of Pesticide Exposure and Pathogen Infection on Bee Health - a Critical Analysis. Biol Rev Camb Philos Soc (2016) 91(4):1006-19. doi: 10.1111/brv.12206

193. Marshall D, Schneemann A. Specific Packaging of Nodaviral RNA2 Requires the N-Terminus of the Capsid Protein. Virology (2001) 285(1):165-75. doi: $10.1006 /$ viro.2001.0951

194. Rice CM, Levis R, Strauss JH, Huang HV. Production of Infectious RNA Transcripts From Sindbis Virus cDNA Clones: Mapping of Lethal Mutations, Rescue of a Temperature-Sensitive Marker, and In Vitro Mutagenesis to Generate Defined Mutants. J Virol (1987) 61(12):3809-19. doi: 10.1128/JVI.61.12.3809-3819.1987 
195. Lin CH, Sponsler DB, Richardson RT, Watters HD, Glinski DA, Henderson WM, et al. Honey Bees and Neonicotinoid-Treated Corn Seed: Contamination, Exposure, and Effects. Environ Toxicol Chem (2021) 40 (4):1212-21. doi: 10.1002/etc.4957

196. Blacquière T, Smagghe G, van Gestel CAM, Mommaerts V. Neonicotinoids in Bees: A Review on Concentrations, Side-Effects and Risk Assessment. Ecotoxicology (2012) 21(4):973-92. doi: 10.1007/ s10646-012-0863-x

197. de Miranda JR, Bailey L, Ball BV, Blanchard P, Budge GE, Chejanovsky N, et al. Standard Methods for Virus Research in Apis Mellifera. J Apicult Res (2013) 52(4):1-56. doi: 10.3896/IBRA.1.52.4.22

198. Ginzinger DG. Gene Quantification Using Real-Time Quantitative PCR: An Emerging Technology Hits the Mainstream. Exp Hematol (2002) 30(6):50312. doi: $10.1016 / \mathrm{s} 0301-472 \mathrm{x}(02) 00806-8$

199. Bauer DF. Constructing Confidence Sets Using Rank Statistics. J Am Stat Assoc (1972) 67(339):687-90. doi: 10.1080/01621459.1972.10481279
Conflict of Interest: The authors declare that the research was conducted in the absence of any commercial or financial relationships that could be construed as a potential conflict of interest.

Publisher's Note: All claims expressed in this article are solely those of the authors and do not necessarily represent those of their affiliated organizations, or those of the publisher, the editors and the reviewers. Any product that may be evaluated in this article, or claim that may be made by its manufacturer, is not guaranteed or endorsed by the publisher.

Copyright (c) 2021 Parekh, Daughenbaugh and Flenniken. This is an open-access article distributed under the terms of the Creative Commons Attribution License (CC BY). The use, distribution or reproduction in other forums is permitted, provided the original author(s) and the copyright owner(s) are credited and that the original publication in this journal is cited, in accordance with accepted academic practice. No use, distribution or reproduction is permitted which does not comply with these terms. 